A 1Ј103087224

NT

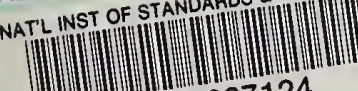

A11103087124

A111030871

The Destructive bond poul, 19

NBS SPECIAL PUBLICATION 400-18

U.S. DEPARTMENT OF COMMERCE / National Bureau of Standards

Semiconductor Measurement Technology:

\title{
The Destructive Bond Pull Test
}

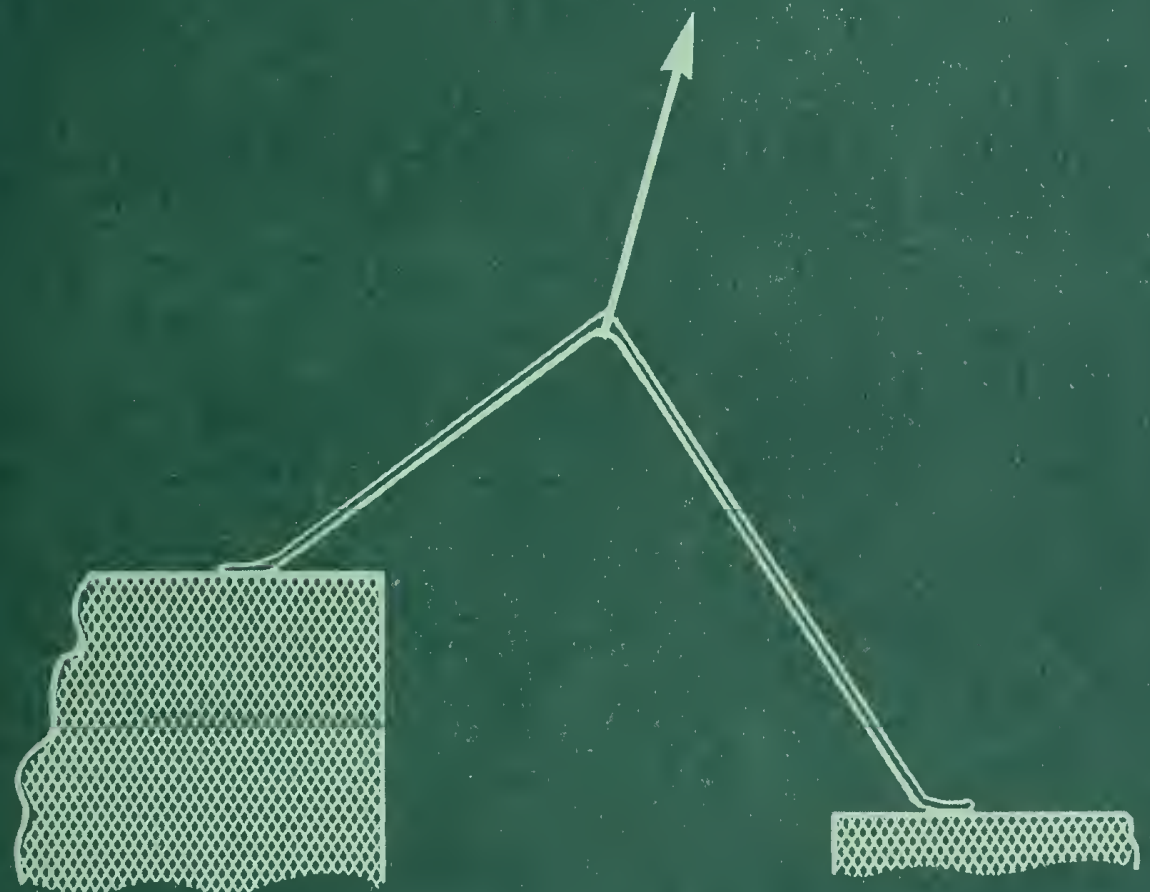




\section{NATIONAL BUREAU OF STANDARDS}

The National Bureau of Standards ${ }^{1}$ was established by an act of Congress March 3, 1901. The Bureau's overall goal is to strengthen and advance the Nation's science and technology and facilitate their effective application for public benefit. To this end, the Bureau conducts research and provides: (1) a basis for the Nation's physical measurement system, (2) scientific and technological services for industry and government, (3) a technical basis for equity in trade, and (4) technical services to promote public safety. The Bureau consists of the Institute for Basic Standards, the Institute for Materials Research, the Institute for Applied Technology, the Institute for Computer Sciences and Technology, and the Office for Information Programs.

THE INSTITUTE FOR BASIC STANDARDS provides the central basis within the United States of a complete and consistent system of physical measurement; coordinates that system with measurement systems of other nations; and furnishes essential services leading to accurate and uniform physical measurements throughout the Nation's scientific community, industry, and commerce. The Institute consists of the Office of Measurement Services, the Office of Radiation Measurement and the following Center and divisions:

Applied Mathematics - Electricity - Mechanics - Heat - Optical Physics - Center for Radiation Research: Nuclear Sciences; Applied Radiation - Laboratory Astrophysics ${ }^{2}$ - Cryogenics $^{2}$ - Electromagnetics ${ }^{2}$ - Time and Frequency ${ }^{2}$.

THE INSTITUTE FOR MATERIALS RESEARCH conducts materials research leading to improved methods of measurement, standards, and data on the properties of well-characterized materials needed by industry, commerce, educational institutions, and Government; provides advisory and research services to other Government agencies; and develops, produces, and distributes standard reference materials. The Institute consists of the Office of Standard Reference Materials, the Office of Air and Water Measurement, and the following divisions:

Analytical Chemistry - Polymers - Metallurgy - Inorganic Materials - Reactor Radiation - Physical Chemistry.

THE INSTITUTE FOR APPLIED TECHNOLOGY provides technical services to promote the use of available technology and to facilitate technological innovation in industry and Government; cooperates with public and private organizations leading to the development of technological standards (including mandatory safety standards), codes and methods of test; and provides technical advice and services to Government agencies upon request. The Institute consists of the following divisions and Centers:

Standards Application and Analysis - Electronic Technology - Center for Consumer Product Technology: Product Systems Analysis; Product Engineering - Center for Building Technology: Structures, Materials, and Life Safety; Building Environment; Technical Evaluation and Application - Center for Fire Research: Fire Science; Fire Safety Engineering.

THE INSTITUTE FOR COMPUTER SCIENCES AND TECHNOLOGY conducts research and provides technical services designed to aid Government agencies in improving cost effectiveness in the conduct of their programs through the selection, acquisition, and effective utilization of automatic data processing equipment; and serves as the principal focus within the executive branch for the development of Federal standards for automatic data processing equipment, techniques, and computer languages. The Institute consists of the following divisions:

Computer Services - Systems and Software - Computer Systems Engineering - Information Technology.

THE OFFICE FOR INFORMATION PROGRAMS promotes optimum dissemination and accessibility of scientific information generated within NBS and other agencies of the Federal Government; promotes the development of the National Standard Reference Data System and a system of information analysis centers dealing with the broader aspects of the National Measurement System; provides appropriate services to ensure that the NBS staff has optimum accessibility to the scientific information of the world. The Office consists of the following organizational units:

Office of Standard Reference Data - Office of Information Activities - Office of Technical Publications - Library - Office of International Relations - Office of International Standards.

1 Headquarters and Laboratories at Gaithersburg, Maryland, unless otherwise noted; mailing address Washington, D.C. 20234.

2 Located at Boulder, Colorado 80302. 


\section{The Destructive Bond Pull Test}

John Albers, Editor

Electronic Technology Division

Institute for Applied Technology

National Bureau of Standards

Washington, D.C. 20234

Jointly supported by:

The National Bureau of Standards,

The Defense Nuclear Agency, and

The Navy Strategic Systems Project Office

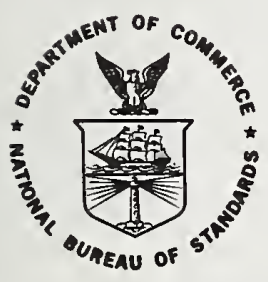

U.S. DEPARTMENT OF COMMERCE, Elliot L. Richardson, Secretary Designate

James A. Baker, III, Under Secretary

Dr. Betsy Ancker-Johnson, Assistant Secretary for Science and Technology

NATIONAL BUREAU OF STANDARDS, Ernest Ambler, Acting Director

Issued February 1976 
Library of Congress Cataloging in Publication Data Main entry under title:

Semiconductor measurement technology.

(National Bureau of Standards special publication; 400-18)

"Jointly supported by: the National Bureau of Standards, the Defense Nuclear Agency, and the Navy Strategic Systems Project Office."

Supt. of Docs. no.: C 13.10:400-18

1. Aluminum wire-Testing. I. Albers, John. II. Series: United States. National Bureau of Standards. Special publication; 400 . 18. QC100.U57 no.400-18. [TK3307] 602'.ls [621.8'54'021] 75 . 619425

\section{National Bureau of Standards Special Publication 400-18}

Nat. Bur. Stand. (U.S.), Spec. Publ. 400-18, 52 pages (Feb. 1976)

CODEN: XNBSAV 
Semiconductor Measurement Technology:

THE DESTRUCTIVE BOND PULL TEST

Preface ................................. vi

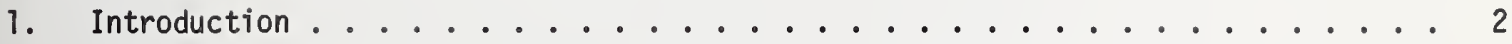

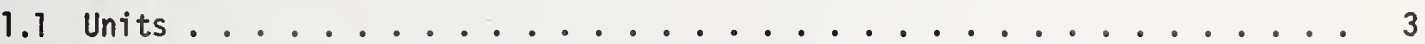

2. Resolution-of-Forces Calculation ................. 4

3. Fabrication of Test Specimens .................... 9

4. Variables Involved in Resolution-of-Forces Calculation . . . . . . . . . 11

4.1 Position of Hook $(\varepsilon)$.......................... 11

4.1 .1 Single-Level Bonds ...................... 11

4.1.2 Two-Level Bonds ....................... 11

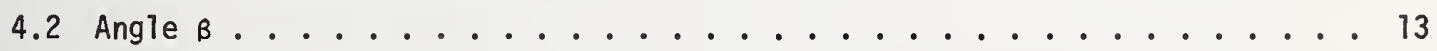

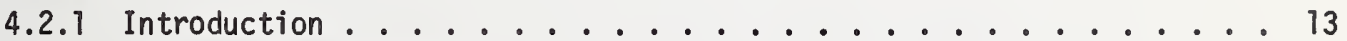

4.2.2 Singte-Level Bonds ................. . . . 13

4.2.3 Two-Levet Bonds ......................... 13

4.3 Loop Height $(h)$. . . . . . . . . . . . . . . . 16

4.3.1 Single-Level Unannealed Bonds . . . . . . . . . . 16

4.3.2 Single-Level Annealed Bonds .............. 18

4.3.3 Two-Levet Bonds ................... 20

5. Variables Not Involved in Resolution-of-Forces Calculation . . . . . . . 22

5.1 Rate of Pull . . . . . . . . . . . . . . . . 22

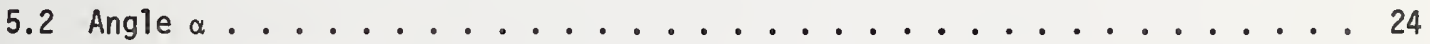

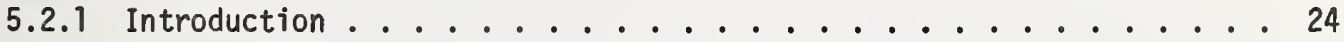

5.2 .2 Single-Level Bonds . . . . . . . . . . . . . . 24

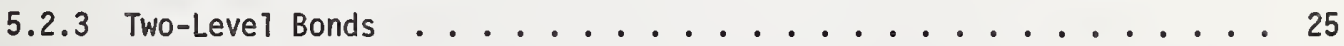

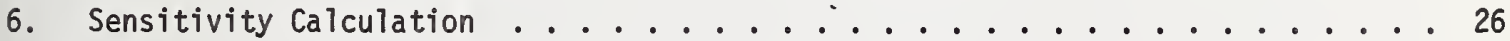

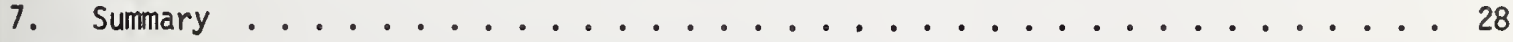

References ........................... . . 29

Appendix A. Resolution-of-Forces Calculation . . . . . . . . . . . 31

Appendix B. Programs Used for Resolution-of-Forces
Calculation . . . . . . . . . . . . . . . . 33

Appendix C. Bond Pull Specifications for Large-

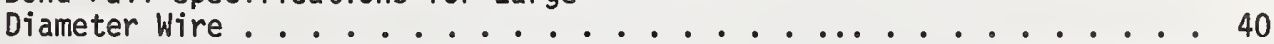

Appendix D. Non-Destructive Wire Bond Pull Test . . . . . . . . . . . . 42 
1. Geometric variables for the bond pull test . . . . . . . . . . . . 6

2. Dependence of $F_{w t} / F$ on $\theta_{t}$ for various ratios of $\theta_{d}$ to $\theta_{t}$. 3. $F_{w t} / F$ as a function of $d / h$ for different values of $H / h$ for

4. $\mathrm{F}_{\mathrm{Wd}} / \mathrm{F}$ as a function of $\mathrm{d} / \mathrm{h}$ for different values of $\mathrm{H} / \mathrm{h}$ for

5. Scanning electron micrograph of bond pad.array used for single-

level studies

6. Pictorial illustration of two-level substrate . . . . . . . . . . . 10

7. Measured pull strength of single-level bonds for different

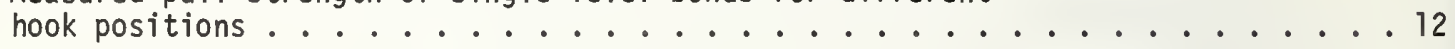

8. Measured pull strength of two-level bond pairs as a function

of the position of the pulling hook ...................... 12

9. Geometrical variables for the pull test for bonds made on two-

level substrates for pulling normal to the substrate . . . . . . . . . 14

10. Measured pull strength of single-level bond pairs as a

function of the angle of pull in the plane of the bond loop ......... 14

11. Pull configuration for two-level bonds . . . . . . . . . . . . . 15

12. Measured pull strength of bond pairs as a function of the

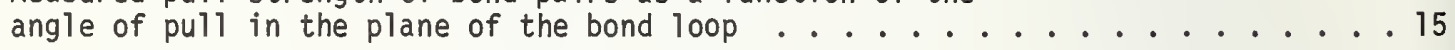

13. Measured pull strength as a function of the bond angle $(\theta)$. . . . . . . . 17

14. Pull strength of unannealed round-wire bonds as a function

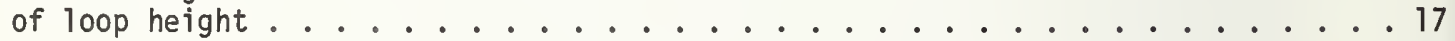

15. Pull strength of ribbon-wire as a function of loop height . . . . . . . 19

16. Pull strength of unannealed round-wire bonds and annealed round-wire bonds as a function of loop height . . . . . . . . . . . 19

17. Measured pull strength of unannealed, round-wire, two-

level bonds as a function of loop height above the high pad . . . . . . . . 21

18. Normalized pull strength of unannealed, round-robin, two-level

bonds as a function of loop height above the high pad . . . . . . . . . . 21

19. Measured bond pul1 strength as a function of pull rate . . . . . . . . . 23

20. Normalized pull strength as a function of pull angle, $\alpha$, for round-wire bonds with small and large deformation .............. 23

21. Normalized pull strength as a function of angle of pull, $\alpha$, for two-level bond pairs 
22. Normalized variation in calculated pull strength for the terminal bond, $\Delta F(t)$, and die bond, $\Delta F(d)$, as a function

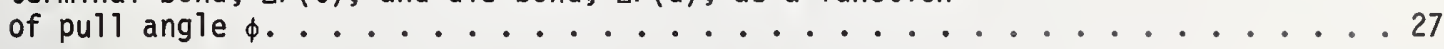

A1. Vector diagram for resolution-of-forces operative in bonded system during application of pulling force . . . . . . . . . . 32

$\mathrm{Cl}$. Minimum destructive bond pull breaking-force vs. wire diameter for aluminum wire bonds in semiconductor devices . . . . . . . . . . 41

D1. Stress-strain curves for annealed $(A)$ and hard-drawn or stress-relieved (B) aluminum wire

\section{LIST OF TABLES}

1. Typical results for resolution-of-forces calculation for single-level and two-level bonds

2. Calculated dependence of $\Delta F(t)$ and $\Delta F(d)$ on pull test conditions for

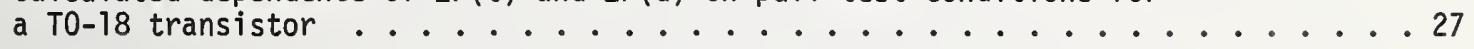

B1. HP-65 Program for Resolution-of-Forces Calculation . . . . . . . . . . 34

B2. Basic Program for Resolution-of-Forces Calculation . . . . . . . . . 35

B3. Fortran Program for Resolution-of-Forces Calculation . . . . . . . . . . 38

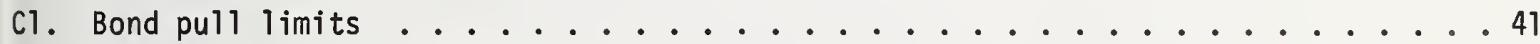

D1. Summary of NDP force recommendations . . . . . . . . . . . . . 43 
The Semiconductor Technology Program serves to focus NBS efforts to enhance the performance, interchangeability, and rellability of discrete semiconductor devices and integrated circuits through improvements in measurement technology for use in specifying materials and devices in national and international commerce and for use by industry in controlling device fabrication processes. Its major thrusts are the development of carefully evaluated and well documented test procedures and associated technology and the dissemination of such information to the electronics community. Application of the output by industry will contribute to higher ylelds, lower cost, and higher reliability of semiconductor devices. The output provides a common basis for the purchase specifications of government agencies which will lead to greater economy in government procurement. In addition, improved measurement technology will provide a basis for controlled improvements in fabrication processes and in essential device characteristics.

The work described in this report has been jointly sponsored by the Defense Nuclear Agency, the U.S. Navy Strategic Systems Project Office (Code SP-23, administered by Naval Ammunition Depot, Crane, Indiana), and the National Bureau of Standards. 


\author{
John Albers, Editor \\ Institute for Applied Technology \\ National Bureau of Standards \\ Washington, D.C. 20234
}

ABSTRACT

This report summarizes the work done at NBS on the destructive bond pull test as applied to small-diameter (approximately 1 mil or $25 \mu \mathrm{m}$ ) ultrasonically bonded aluminum wire. This work was performed during the period from 1969 to 1974. The report begins with a brief summary of the calculation of the resolution-of-forces operative in the bond system during the application of the pulling force. Next, comparisons of the theoretical and experimental dependencies of the pull strength on the variables involved in the resolution-of-forces calculation are given. Some of the variables which are not directly involved in this calculation are then considered and their effects on the measured pull strength are presented. The report ends with a sensitivity calculation as to how well the variables must be controlled to maintain the variability of the pull strength within given limits.

Bond pull specifications for large-diameter wire as well as recommended force levels to be used in the application of the nondestructive bond pull test, both of which have resulted from the pull test work, are considered in the appendices.

Key Words: Bond angle; bonding; bond pull test; bond-to-bond spacing; large wire; loop height; microelectronics; non-destructive bond pull test; position of hook, pull rate; pull strength; resolution-of-forces; semiconductor devices; ultrasonic bonding; wire bond. 


\section{INTRODUCTION}

This report is an edited summary of the NBS effort on the destructive bond pull test. The rationale for this work lies in the widespread use of this test method in the electronics industry to evaluate the mechanical strength of wire bonds in semiconductor devices and in the large gap between the use of the pull test and the acquisition of reproductble calculable quantities which could be used to quantify the test results. Hence, at the request of several agencies, and with the guidance of standards organizations, an extensive survey of test methods for wire bonds in general [1] and an evaluation of the pull test in particular were begun.

Initial in-house efforts to produce reproducible wire bonds to be used in the evaluation showed that the currently practiced industrlal procedures were inadequate. This led to a study of ultrasonic wire bonding techniques. The results of this study pointed to the lack of shock and vibration isolation and the subsequent bond variability due to environmental and operator induced stresses as being primarlly responsible for this inadequacy. An offshoot of this investigation was a better understanding of ultrasonic bonding through the use of magnetic pickup, capacitor microphone, and low-power laser detectors of tool motion during the bonding process. Optimized bond quality through bonding schedule studies resulted from this study. An exposition of a mechanism for the formation of ultrasonic bonds also followed from this study. A detalled treatment of these facets of the NBS work appears elsewhere [2].

Once bonder and related problems were solved, work was begun to quantify the results of the pull test. In order to carry out this program, it was necessary to correlate the measured pull strength as determined in the pull test with the stress in the wire, which depends on the geometry of the bond system. This was done through the resolution-of-forces calculation. An extensive series of experiments was undertaken in order to relate observed pull strengths to the results of the resolution-of-forces calculation. To further enhance the understanding of the pull test, certain varlables which could not be introduced in the two-dimensional resolution-of-forces calculation were experimentally studied to ascertain their effects on the pull test results. This report is concerned with the results and conclusions of this investigation.

The results of the pull test work have been used by ASTM Committee F-1 on Electronics in the preparation of a document on the pull test method. At the time of this writing, the document is well on 1 ts way to becoming an accepted standard. To support this evolution, a round robin is presently being run using test vehicles prepared at NBS. On each specimen, three groups of bonds of different deformation were prepared. One-half of the bonds of each group were pulled to destruction at NBS and the remaining half were pulled at the individual laboratories participating in the round robin. The round robin is not complete; however, preliminary results indicate that the mean pull strengths as determined by NBS and by each of the other participating laboratories differ by about ten percent. It should be noted that these conclusions are preliminary and are based upon raw data. A more 
complete treatment of the round robin and the data analysis will appear in the future when the round robin is complete.

The better understanding of the pull test has led to other developments. These include a bond pull specification for large diameter wire as well as statistical and metallurgical rationales for a nondestructive wire bond pull test. These are discussed in appendices $C$ and $D$ respectively. The work on the nondestructive pull test is also being used by ASTM Committee F-1 on Electronics in the development of a recommended practice for carrying out this type of test.

The following section contains a brief summary of a calculation of the resolution of the forces operative in the bond system during the application of the pulling force. A more complete derivation is presented in Appendix A and programs (in several different languages) which may be used for numerical calculation of the resolution-of-forces equations are given in Appendix $B$.

The discussion of the resolution-of-forces calculation is followed in Section 3 by a description of the fabrication of the specimens used for the single-level and two-level bond studies.

In Section 4, comparisons of the theoretical and experimental dependencies of the pull strength on the variables which are involved in the resolution-of-forces calculation are given. Of particular importance are the loop height, the position of the hook, and the angle between the direction of the pulling force and the normal to the line joining the bond terminals.

In Section 5, consideration is given to some of the variables which are not directly involved in the resolution of forces calculation. The variables considered are the rate of pull and the angle between the direction of pull and the normal to the substrate in the plane perpendicular to both the substrate and the plane of the bond loop.

Section 6 contains a sensitivity computation from which it can be estimated how well the variables must be controlled in order to maintain the accuracy of the results to within a given interval. A summary of the results comprises the final portion of the report.

\subsection{UNITS}

The American semiconductor industry has traditionally used mixed English and metric units, but presently there is a trend in the direction of the International System (SI) units. For the purposes of conversion, it should be noted that $1 \mathrm{mil}=0.001 \mathrm{in}$. $=25.4 \mu \mathrm{m}$ and that 1 gram force $(\mathrm{gf})=9.8$ millinewtons $(\mathrm{mN})$. 


\section{RESOLUTION-OF-FORCES CALCULATION}

The destructive bond pull test, more commonly called simply the pull test, is one of the most widely used test methods employed in the evaluation of the quality of wire bond systems. In its elemental form, the test consists of pulling the wire span between the bond on the terminal and the bond on the semiconductor die with a hook assembly until rupture takes place. The pulling force at which rupture occurs is usually referred to as the pull strength of the bond. The pull force at rupture is most frequently presented in units of grams force.

An analysis of the resolution-of-forces provides relationships between the pull strength and the forces in the bond system at mpture. In figure 1, the geometrical variables are presented for a typical two-level bond. The angle $\phi$ is that between the direction of the applied force $F$ and the normal to the substrate. At the bond on the semiconductor die, the angle between the wire and the surface of the die is denoted by $\theta_{d}$. At the terminal, the angle between the wire and the plane of the terminal surface is denoted by $\theta_{t}$. The forces in the wire at the terminal and die are designated by $F_{w t}$ and $F_{w d}$, respectively. These forces are related to the applied pull force as follows:

$$
\begin{aligned}
& F_{w t}=F\left[\frac{\cos \left(\theta_{d}-\phi\right)}{\sin \left(\theta_{t}+\theta_{d}\right)}\right], \\
& F_{w d}=F\left[\frac{\cos \left(\theta_{t}+\phi\right)}{\sin \left(\theta_{t}+\theta_{d}\right)}\right] .
\end{aligned}
$$

For the simple case of a single-level bond pulled normal to the substrate and at the middle of the wire span, $\phi=0$ and $\theta_{t}=\theta_{d}=\theta$. In this instance, the above equations reduce to

$$
\mathrm{F}_{\mathrm{wd}}=\mathrm{F}_{\mathrm{wt}}=\mathrm{F} \frac{1}{2 \sin \theta} .
$$

The angular variables $\theta_{\mathrm{t}}$ and $\theta_{\mathrm{d}}$ are often difficult to measure. However, the angles may be related to the variables $h, H$, d, and $\varepsilon$ which are more easily accessible to measurement. It may be seen from figure 1 that $h$ is the height of the wire span (at the point of pull) above the terminal contact surface. The vertical distance between the terminal contact surface and the semiconductor die surface is denoted by $\mathrm{H}$. The horizontal distance between the bond on the terminal and the bond on the die is denoted by $\mathrm{d}$ and is usually referred to as the bond-to-bond spacing. Finally, $\varepsilon$, where $0 \leqslant \varepsilon \leqslant 1$, is the dimensionless fractional horizontal distance between the terminal bond and the point of application of the pulling force. In terms of these distance variables, $\mathrm{F}_{\mathrm{wd}}$ and $\mathrm{F}_{\mathrm{wt}}$ are related to $\mathrm{F}$ for a two-level bond as follows:

$$
F_{w t}=F^{\left.\left(1+\frac{\varepsilon^{2} d^{2}}{h^{2}}\right)^{\frac{1}{2}}\left[(1-\varepsilon) \cos \phi+\frac{(h+H) \sin \phi}{d}\right]\right)} \text {, }
$$




$$
\left.F_{w d}=F \frac{\left.\left(1+\frac{(1-\varepsilon)^{2} d^{2}}{(h+H)^{2}}\right)^{\frac{1}{2}}\left[1+\frac{H}{h}\right]\left\{\varepsilon \cos \phi-\frac{h \sin \phi}{d}\right\}\right)}{1+\frac{\varepsilon H}{h}}\right\}
$$

If the bond is pulled normal to the substrate $(\phi=0)$, eqs ( 4 ) and (5) reduce to

$$
\begin{aligned}
& F_{w t}=F\left(\frac{(1-\varepsilon)}{1+\frac{\varepsilon H}{h}}\left[1+\frac{\varepsilon^{2} d^{2}}{h^{2}}\right]^{\frac{1}{2}}\right) \text { and, } \\
& F_{w d}=F\left(\frac{\varepsilon\left[1+\frac{H}{h}\right]}{1+\frac{\varepsilon H}{h}}\left[1+\frac{(1-\varepsilon)^{2} d^{2}}{(h+H)^{2}}\right]^{\frac{1}{2}}\right) .
\end{aligned}
$$

For a single-level bond which is pulled at mid-span, in a direction normal to the substrate, both $\phi$ and $H$ are zero and $\varepsilon$ is equal to one-half. Under these conditions, eqs (4) and (5) reduce to

$$
F_{w t}=F_{w d}=\frac{F}{2}\left[1+\left(\frac{d}{2 h}\right)^{2}\right]^{\frac{1}{2}} \text {. }
$$

It should be noted that eqs (1) through (8) may be used for calculating pull strengths only when heel breakage (tensile failure) is observed.

For the convenience of readers interested in numerical computations, Appendix B contains programs in several different languages which make use of eqs (4) and (5) to calculate the pull strength. For purposes of graphical illustration of the predictions of eqs (1) through (8), plots of the force in the wire on the terminal or die divided by the pulling force as functions of the angular variables or the length variables are presented in figures 2 to 4 . Also, table 1 contains typical results from the resolution-offorces calculation for single-level and two-level bonds [3]. 


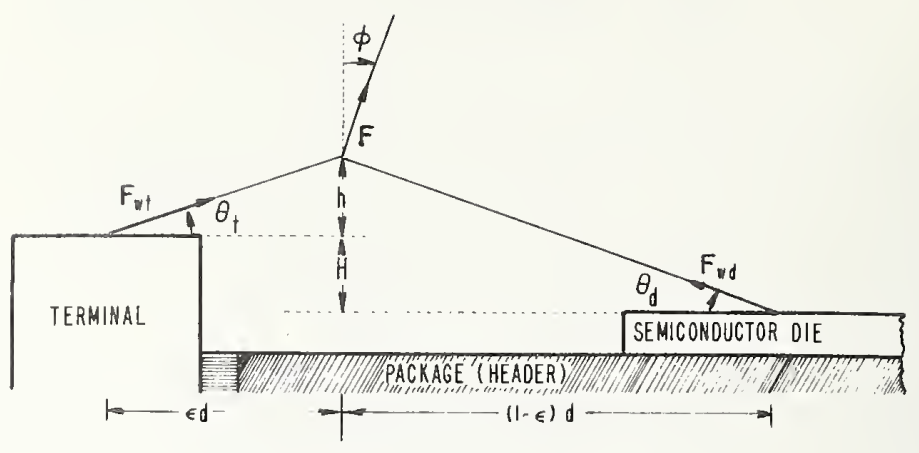

Figure 1. Geometric variables for the bond pull test.

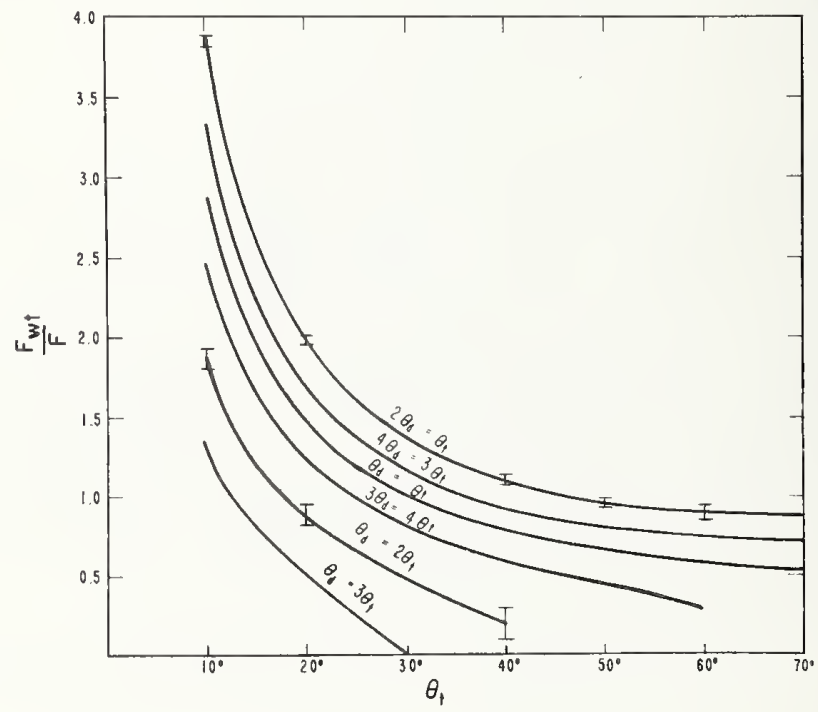

Figure 2. Dependence of $F_{w t} / F$ on $\theta_{t}$ for various ratios $\theta_{d}$ to $\theta_{t}$. (The curves are for the case $\phi=0$. Horizontal bars above and below the curves for ${ }^{2 \theta_{d}}=\theta_{t}$ show the effect of changing $\phi$ to plus and minus $5 \mathrm{deg}$, respectively. To obtain the dependence of $F_{w t} / F$, interchange everywhere the subscripts $d$ and $t$ and change the sign of $\phi)$. 


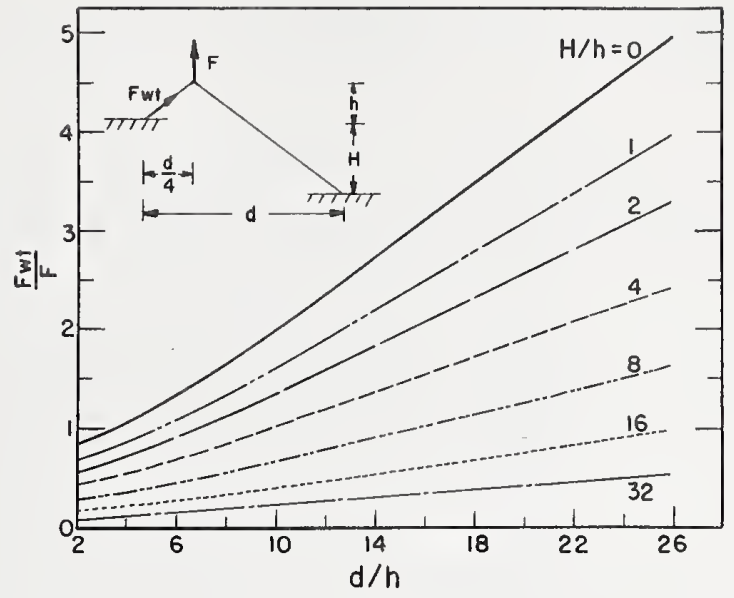

Figure 3. $F_{w t} / F$ as a function of $d / h$ for different values of $\mathrm{H} / \mathrm{h}$ and for $\varepsilon=1 / 4$.

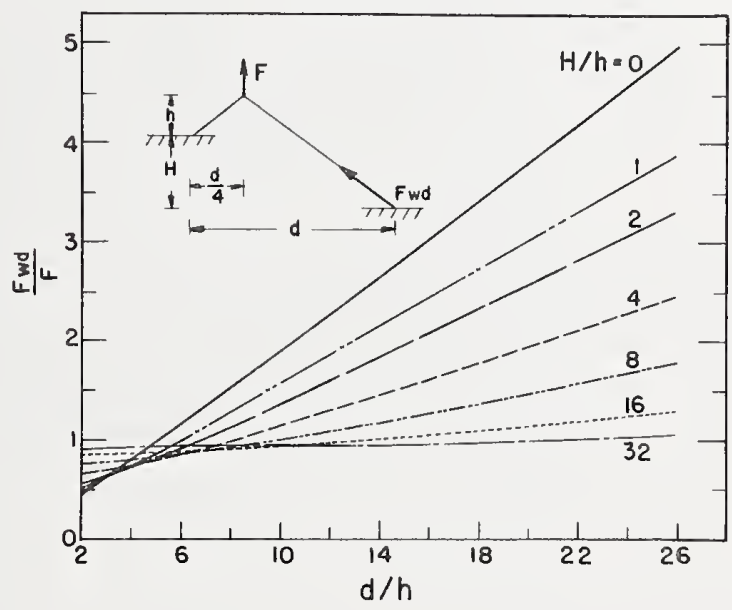

Figure 4. $F_{w d} / F$ as a function of $d / h$ for different values of $H / h$ and for $\varepsilon=1 / 4$. 
Table 1. Typical Results from Resolution-of-Forces Calculation for single-Level and Two-Level Bonds

\begin{tabular}{|c|c|c|c|c|}
\hline Single Level & $H=0$ & $d=1.0 \mathrm{~mm}$ & \multicolumn{2}{|c|}{$F=10 \mathrm{gf}$} \\
\hline$h(m m)$ & $\varepsilon$ & $\phi($ deg $)$ & Fwt (gf) & $F_{w d}(g f)$ \\
\hline 0.1 & 0.50 & 0 & 25.5 & 25.5 \\
\hline 0.2 & 0.50 & 0 & 13.46 & 13.46 \\
\hline 0.3 & 0.50 & 0 & 9.72 & 9.72 \\
\hline 0.4 & 0.50 & 0 & 8.00 & 8.00 \\
\hline 0.5 & 0.50 & 0 & 7.07 & 7.07 \\
\hline 0.3 & 0.25 & 0 & 9.76 & 6.73 \\
\hline 0.3 & 0.50 & 0 & 9.72 & 9.72 \\
\hline 0.3 & 0.75 & 0 & 6.73 & 9.76 \\
\hline 0.3 & 0.50 & -10 & 8.56 & 10.58 \\
\hline 0.3 & 0.50 & 0 & 9.72 & 9.72 \\
\hline 0.3 & 0.50 & 10 & 10.58 & 8.56 \\
\hline Two Level & $H=0.5 \mathrm{~mm}$ & $\mathrm{~d}=1.0 \mathrm{~mm}$ & \multicolumn{2}{|c|}{$F=10 \mathrm{gf}$} \\
\hline$h(\mathrm{~mm})$ & $\varepsilon$ & $\phi($ deg $)$ & Fwt (gf) & Fwd $(g f)$ \\
\hline 0.1 & 0.50 & 0 & 7.28 & 11.16 \\
\hline 0.2 & 0.50 & 0 & 5.98 & 9.56 \\
\hline 0.3 & 0.50 & 0 & 5.30 & 8.58 \\
\hline 0.4 & 0.50 & 0 & 4.93 & 7.92 \\
\hline 0.5 & 0.50 & 0 & 4.71 & 7.45 \\
\hline 0.3 & 0.25 & 0 & 6.89 & 6.45 \\
\hline 0.3 & 0.50 & 0 & 5.30 & 8.58 \\
\hline 0.3 & 0.75 & 0 & 2.99 & 9.31 \\
\hline 0.3 & 0.50 & -10 & 3.75 & 9.34 \\
\hline 0.3 & 0.50 & 0 & 5.30 & 8.58 \\
\hline 0.3 & 0.50 & -10 & 6.69 & 7.55 \\
\hline
\end{tabular}




\section{FABRICATION OF TEST SPECIMENS}

The bonding pads which were used for the work reported were fabricated on 0.010-in. $(0.25-\mathrm{mm})$ thick, $1.0-\mathrm{in} .(25-\mathrm{mm})$ diameter silicon wafers, coated with $0.5 \mu \mathrm{m}$ of steamgrown silicon dioxide and 0.5 to $1 \mu \mathrm{m}$ of evaporated aluminum. The aluminum was etched to leave $0.005-i n$. $(0.13-\mathrm{mm})$ square bonding pads by means of standard photolithographic techniques. An example of the bonding pad array is given in figure 5 [4].

For two-level studies, strips of silicon $0.05-\mathrm{in} .(1.3-\mathrm{mm})$ wide, obtained by scribing and breaking a prepared substrate, were affixed with a high temperature glue to another substrate so that the bonding pad arrays lined up as shown in figure 6 . Thus two-level substrates were obtained with rows of bonding pads raised by the thickness of the silicon strip (about $0.25 \mathrm{~mm}$ ) above the bonding pads on the base substrate. It was necessary to position the silicon strip carefully on the base substrate so that a constant spacing between the upper pad and the lower pad was maintained along the length of the strip [5].

Except where otherwise indicated, the wire bonds tested were 0.001-in. (25- $\mathrm{m}^{\text {) dia- }}$ meter aluminum ( $1 \%$ silicon) wire ultrasonically bonded to the aluminum pads. Also, except where otherwise noted, the bonds were made on a single bonding machine and were tested so as to establish their reproducibility. The variables which were constrained by the mode of fabrication were $d$, the bond-to-bond spacing, and $H$, the height of the terminal above the die. For the experiments reported, $d$ has the value of $1.0 \mathrm{~mm}$ and $H$ has the values of zero (for single-level bonds) or $0.25 \mathrm{~mm}$ (for two-level bonds).

The bonding tools used to fabricate the bonds had a smooth front and a sharp back. The sharp back assists the clamp in severing the wire after the second bond has been formed. However, the sharp back of the tool causes the first bond heel to be slightly more deformed than the second bond heel. The result is that the second bond is stronger under tensile failure (heel breakage) for the same force-power-time combination than the first bond.

As the resolution-of-forces applies to the heel breakage failure mode, the forcepower-time combination for bond fabrication was chosen, except as otherwise indicated, such that heel breakage was the principal failure mechanism. 


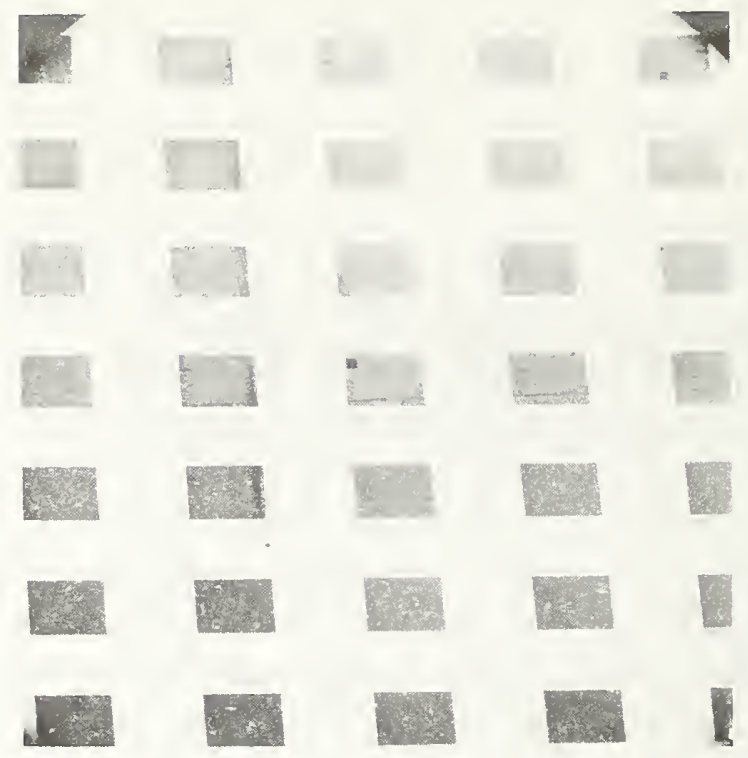

Figure 5. Scanning electron micrograph of bond pad array used for single Jevel studies.

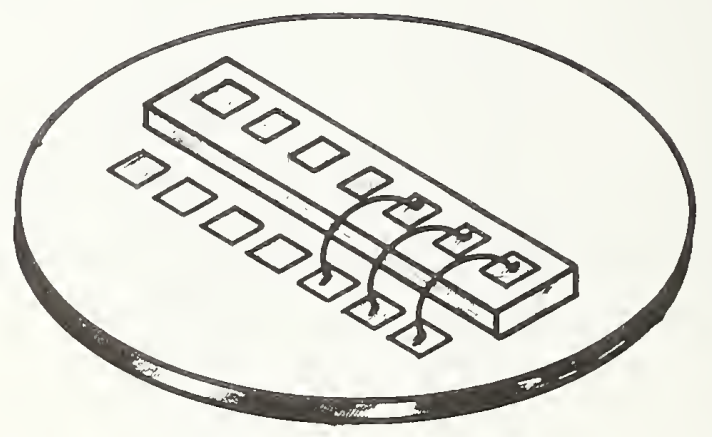

Figure 6. Pictorial illustration of two-level substrate. 


\section{VARIABLES INVOLVED IN THE RESOLUTION OF FORCES CALCULATION}

In this section, consideration is given to the variables which are involved in the resolution-of-forces calculation. These are the position of the hook, $\varepsilon$, the angle $\beta$ (the angle formed between the direction of the pulling force and the normal to the line joining the bond terminals), and the loop height, $h$. In studying each variable, an extensive series of experiments was carried out in order to compare the prediction of the resolution of forces with the measured pull strengths.

\subsection{POSITION OF HOOK $(\varepsilon)$}

\subsubsection{SINGLE-LEVEL BONDS}

An experiment was performed to demonstrate the effect of the position of the pulling hook on the measured pull strength of a single-level ultrasonic bond pair. The results of the experiment are shown in figure 7 in which the measured pull strength, F, of the bond pair is plotted against the position of the hook along the span of wire. The plotted points are the mean pull strength and the error bars represent the 95 percent confidence intervals for the mean.

These experiments indicate that when the wire is pulled on the side nearest the first bond, it is this bond that breaks at the heel due to tensile failure. Conversely, the second bond breaks by tensile failure when the force is applied nearest to it. A transition point, where the probability for either bond to break is nearly the same, occurs at the maximum value of measured pull strength. In the present case this point is found to be displaced more toward the second bond, as might be expected since the bonding machine used in these tests yields a stronger second bond than first.

It should be noted that limited tests on aluminum wire doped with $1 \%$ magnesium rather than silicon indicated, as expected, that there is no difference with respect to the dependence of the pull strength on the geometrical variables. The resolution of forces calculation relates the forces to geometrical variables only, while wire metallurgy determines the tensile strength of the wire [6].

\subsubsection{TWO-LEVEL BONDS}

The effect of varying the position of the pulling hook on pull strength was studied on two-level bond pairs where the first bond was made either to the low pad or to the high pad. Specimen preparation procedures restricted the study to a single value of $H$, the height of the terminal above the die. The results, plotted in figure 8 as measured pull strength normalized to its value at midpoint as a function of hook position, are in agreement with calculations based upon tensile failure except for positions between midpoint and the low pad. It should be noted that in this region the pulling hook was observed to slip along the wire loop toward the midpoint position; thus the measured pull strength lies above the predicted value [5]. 


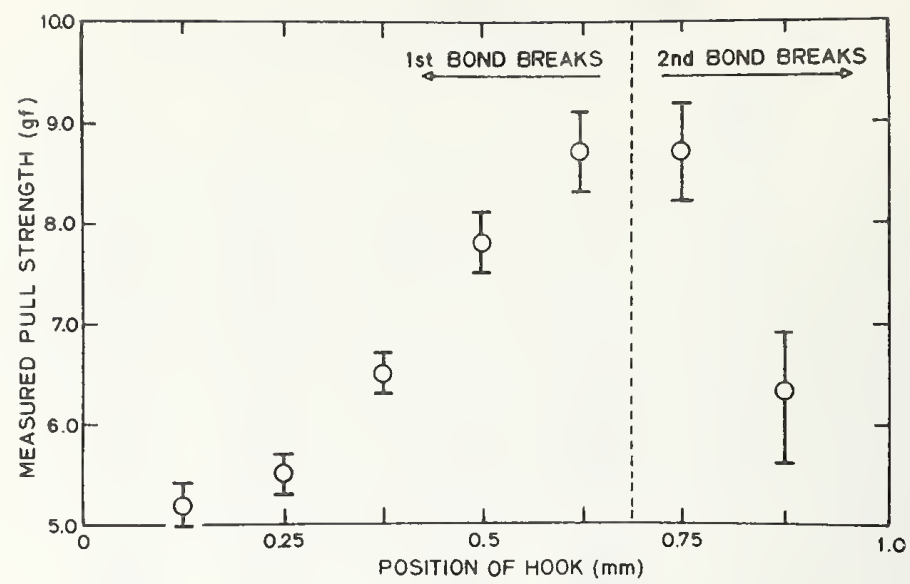

Figure 7. Measured pull strength of single-level bond pairs for different hook positions. (The first bond is at 0 and the second bond is at $1 \mathrm{~mm}$ ).

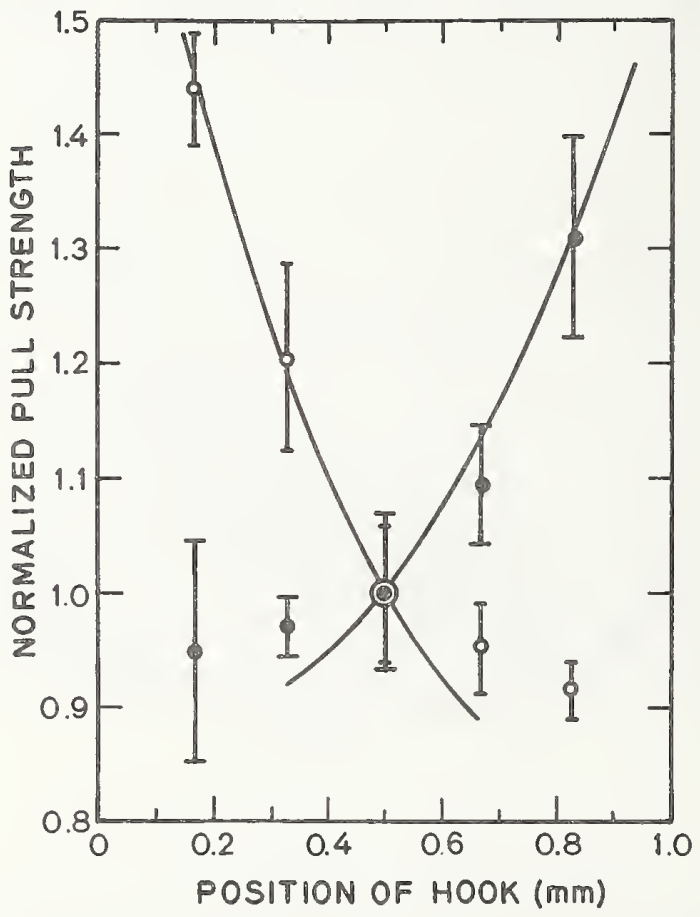

Figure 8. Measured pull strength of two-level bond pairs as a function of the position of the pulling hook. (The values are normalized to the mean pull strength at mid span, $0.5 \mathrm{~mm}$. Solid points are for the first bond made to the high pad; open points are for the first bond made to the low pad. In each case the second bond is at $0 \mathrm{~mm}$ and the first bond is at $1.0 \mathrm{~mm}$. The data points represent the mean of 10 bonds all of which ruptured by tensile failure at the heel of the first bond. Error bars indicate one sample standard deviation above and below the mean. The solid curves were calculated by resolution-of-forces.) 


\subsubsection{INTROOUCTION}

While the discussion of the resolution-of-forces has been cast in terms of the pull angle $\phi$ it is often more convenient to represent the results of pull test experiments (particularly for two-level bonds) in terms of a different angle. This angle, denoted by $\beta$, is defined as that formed between the direction of the pulling force and the normal to the line joining the bond terminals (positive in the direction toward the second bond). The angle $\beta$ is related to the angle $\phi$ by the equation $\beta=\beta_{0} \pm \phi$ where the positive sign obtains if the first bond is the higher (in which case $\beta_{0}$, the angle between the substrate and the line joining the bond terminals, is negative), and the negative sign obtains if the first bond is the lower (in which case $\beta_{0}$ is positive). The various angles are illustrated in figure 9 .

\subsubsection{SINGLE-LEVEL BONDS}

Single-level bond loops were pulled at the midpoint of the loop at angles between 0 and $45 \mathrm{deg}$. in both directions. It should be noted that $\beta_{0}=0$ for single-level systems and hence $\beta=\phi$. The results are shown in figure 10. The mean values of the measured pull strength are denoted by the plotted points and the error bars represent the 95 percent confidence intervals for the mean. The results show higher pull strengths for $B$ negative which is to be expected since the second bond is stronger than the first. When the larger component of the force is applied to the first bond, the measured pull strength is lower and when the larger component of the force is applied to the second bond, the measured pull strength is higher [6].

\subsubsection{TWO-LEVEL BONDS}

The results of the single-level experiments for the larger values of $\beta$ yielded some insight into the pull test for two-level bond pairs. For a two-level bond system, there are two ways the bond loop may typically be positioned for pulling as shown in figure 11 . First, the substrate or package may be held level, which places each of the bonds at different heights, and the force applied in a direction normal to the substrate. Alternative$1 y$, the substrate may be tipped to bring both bonds to the same vertical height; the configuration produced is more nearly similar to a single-level bond case, and the force is applied in a direction normal to an imaginary line joining the two bonds. The configuration in the level substrate case is similar to that of a single-level bond system where the pulling is done at some angle $\beta_{0}$. It is apparent that tipping or not in the two-level bond system is essentially equivalent to varying the angle $\beta$. Although this comparison of single-level and two-level bond systems is in terms of bond loop geometry only, one would expect that the general results shown in figure 10 would be applicable to the twolevel system. That is, if the angle of pull is inclined toward the second bond (applying the larger component of force to the first bond) the measured pull strength is less than if the angle of pull is inclined toward the first bond (applying the larger component of 


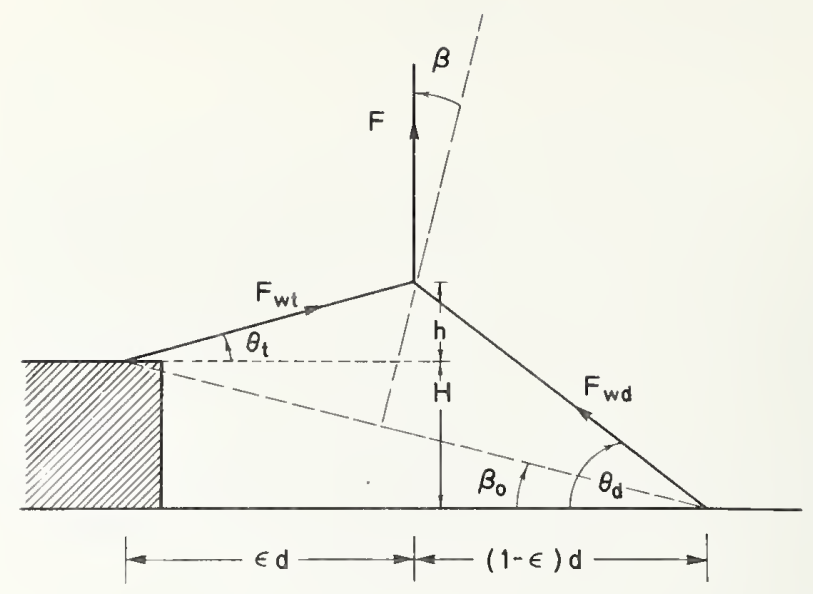

Figure 9. Geometric variables for the pull test for bonds made on two-level substrates for pulling normal to the substrate. (For this case, the angle $\phi$ between the normal to the substrate and the pulling direction is zero. The distance d is the total bond-to-bond spacing in the plane of the substrate.)

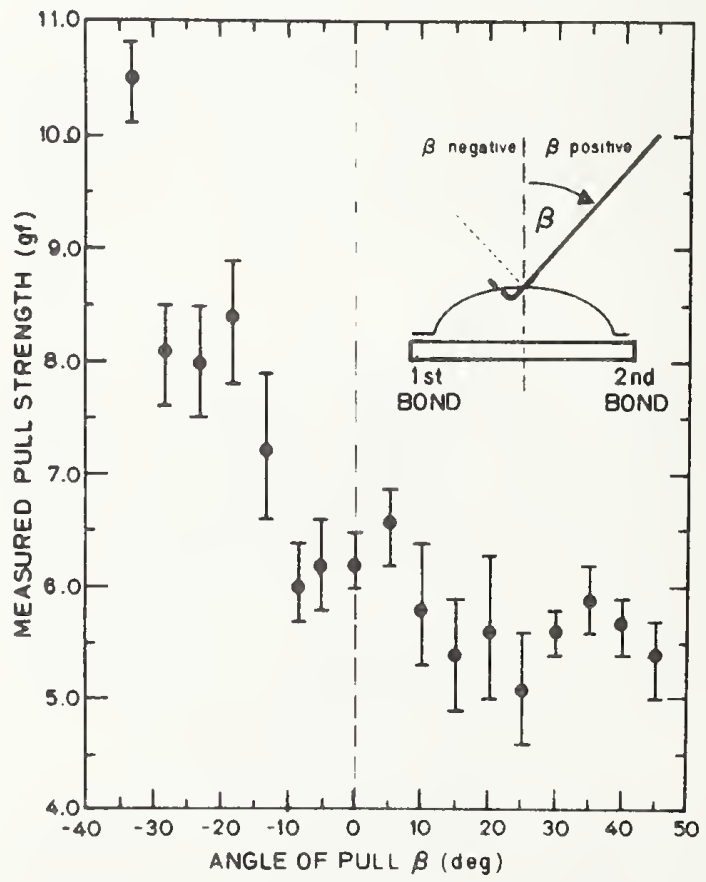

Figure 10. Measured pull strength of single-level bond pairs as a function of the angle of pull in the plane of the bond loop. (The inset shows the relationship of the angle of pull to the normal to the line joining the bonds. Note that the angle is positive when the pull force is inclined toward the second bond and negative when the pull force is inclined toward the first bond.) 

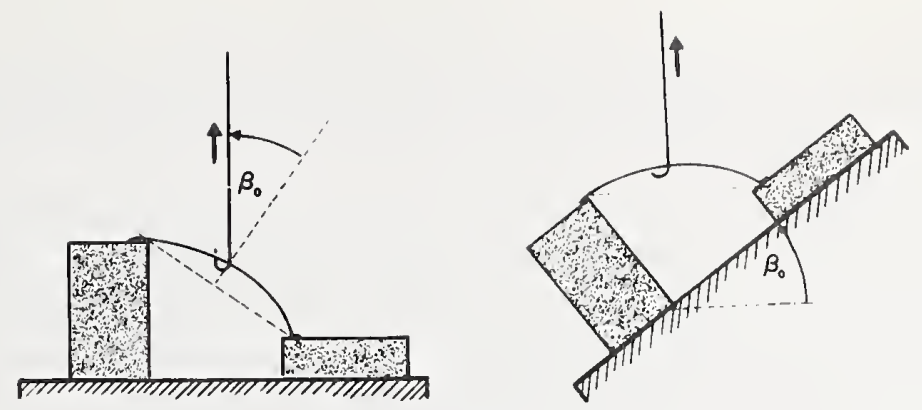

a. Level substrate; nominal pull angle $\beta=\beta_{0}$.

b. Tipped substrate; nominal pull angle $\beta=0$.

Figure 11. Pull configurations for two-level bonds. (The direction of pull is indicated by the arrow.)

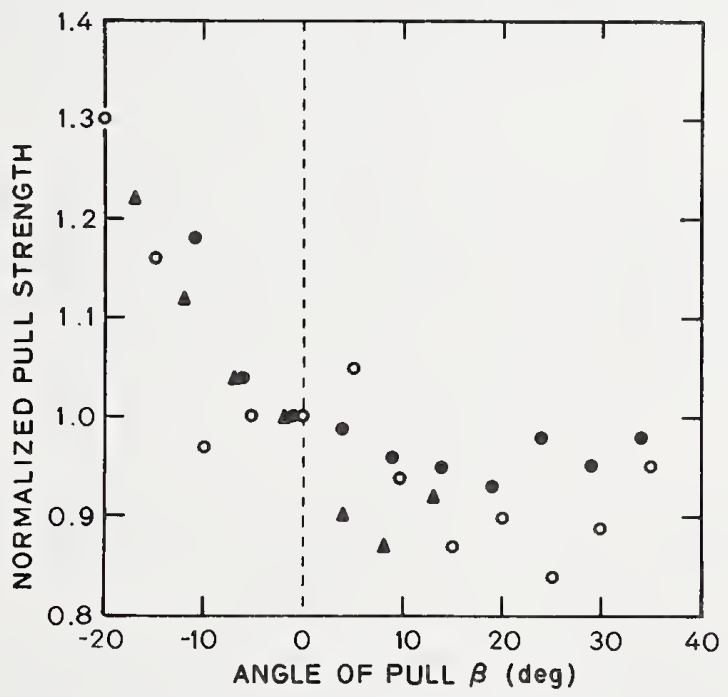

Figure 12. Measured pull strength of bond pairs as a function of the angle of pull in the plane of the bond 1oop. (The values are normalized to the mean pull strength at 0 deg. Solid points are for two-level bond pairs made with the first bond to the high pad (circles) and with the first bond made to the low pad (triangles); open circles are previously reported data for single-level bond pairs. Except for the solid circles, which represent the mean of 30 bonds, the data points represent the mean of 10 bonds, all of which ruptured at the heel of the first bond. Error bars have been omitted to reduce clutter; typically the sample standard deviation is between 0.05 and 0.1. ) 
force to the second bond). However, it should be noted that this analogy does not take into consideration the effects of the angles of the wire at the bond heels for the two situations.

To confirm this hypothesis, the effect of varying the pull angle $B$ was studied for twolevel ultrasonic bond pairs. Measurements of pull strength were made by tilting the substrate while pulling the loop vertically. The results are shown in figure 12 both for bond pairs with the first bond made to the high pad and for bond pairs with the first bond made to the low pad. The pull angle shown is $\beta$ for the former case and $-\beta$ for the latter. For comparison, data for single-level bond pairs are also included; in this case the pull angle is $\phi$, the angle between the direction of pulling force and the normal to the substrate. It can be seen that the trend in all three cases is about the same [5].

\subsection{LOOP HEIGHT (h)}

\subsubsection{SINGLE-LEVEL UNANNEALED BONDS}

A series of tests was conducted to determine the effect of variations in bond angle (or ratio of loop height to bond-to-bond spacing) on the measured pull strength of singlelevel bond pairs pulled at the center of the loop in a direction perpendicular to the plane of the pads. Eight groups of 10 single-level bond pairs were made with different loop heights and spacings. The bond angle varied from 25.7 to $50.3 \mathrm{deg}$. The bond pairs were then pulled to destruction. The exclusive failure mode was breakage at the heel of the first bond.

Results of the experiment are shown in figure 13. The mean measured pull strength and 95 percent confidence intervals for the mean are plotted for each group against the bond angle. The solid curve was calculated from the resolution-of-forces equation for the symmetrical case under study:

$$
F=2 F_{w} \sin \theta
$$

where $F$ is the measured pull strength, $F_{W}$ is the force in the wire, and $\theta$ is the bond angle [7].

A further study was undertaken of the dependence of measured pull strength on loop height or bond angle to gain greater insight into the extent of applicability of the resolution-of-forces calculation. Analysis of the results, shown in figure 14, supports the conclusion that the pull strength calculated by resolution-of-forces does fit the experimental data. Above $\mathrm{h} / \mathrm{d}=1 / 3$, several of the data points $\mathrm{fall}$ below the predicted value of pull strength. This may be explained as follows. As the loop height increases, more normal pulling force is exerted on the bonds. The results of the study of the influence of the bond angle a (see sec 5.2) suggest that this might cause some peeling of the bond before breakage at the heel occurs, which in turn, by stressing a more deformed region, might lower the measured pu11 strength [8].

This conclusion is reinforced by the results of measurements of pull strengths of 


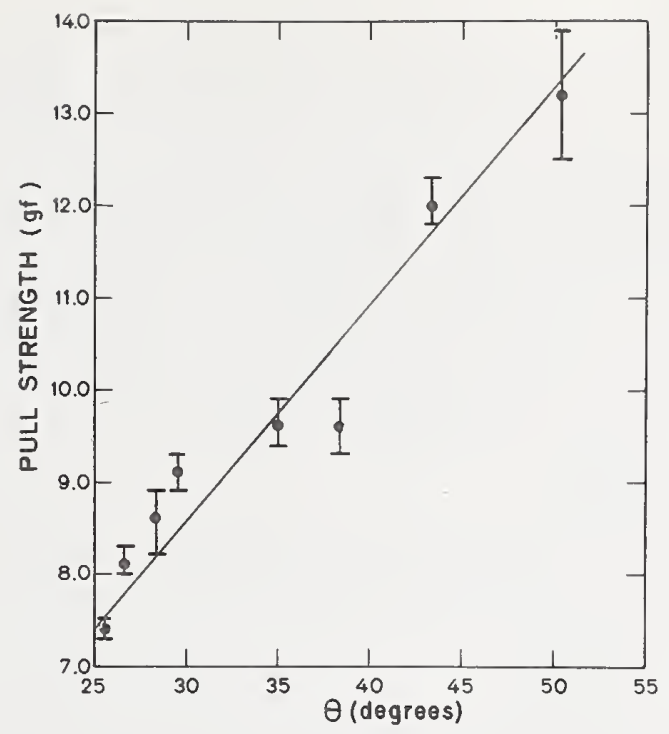

Figure 13. Measured pull strength as a function of bond angle $(\theta)$, (The solid line, $F=17.2 \sin \theta$, is calculated from the resolution-of-forces; the numerical factor is twice the breaking force in the wire. The error bars represent the 95 percent confidence intervals for the means.)

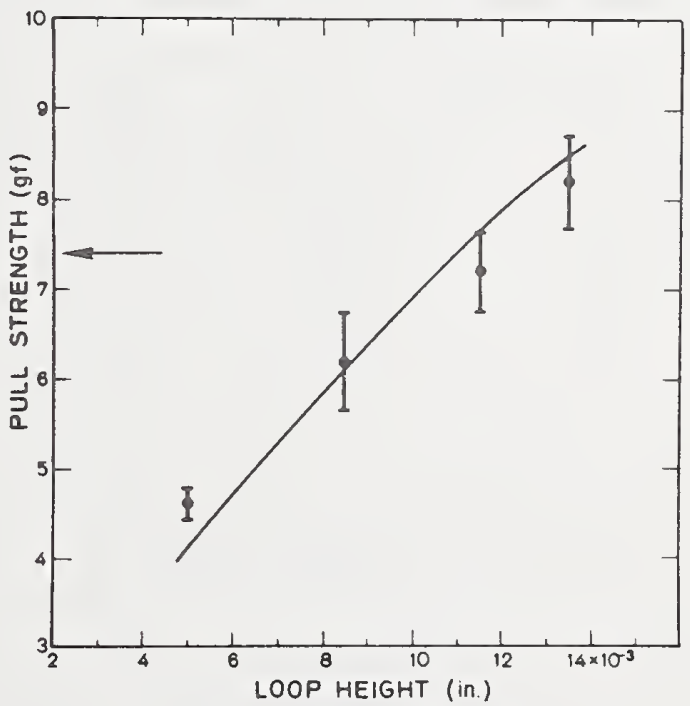

Figure 14. Pull strength of unannealed round-wire bonds as a function of loop height. (The data points represent the mean for up to 10 bonds; only bonds which ruptured at the heel were included. Error bars represent one sample standard deviation. The solid curve is calculated from resolution-offorces using the wire tensile strength indicated by the arrow.) 
0.0015 in $\times 0.0005$ in $(38 \mu \mathrm{m} \times 13 \mu \mathrm{m})$ ribbon-wire bonds as a function of loop height shown in figure 15. The solid data points are average pull strengths for groups of up to 10 bonds each, excluding those bonds that failed due to lift-off of one of the bond pairs. For the two open data points at the two highest loop heights, values resulting from bond lift-offs were included in the average pull strength calculation. Up to a loop height of about $0.010 \mathrm{in} .(0.25 \mathrm{~mm})$, the variation of pull strength as a function of loop height is in agreement with the resolution-nf-forces calculation, but at larger loop heights, the measured pull strength is lower than the predicted value [9].

\subsubsection{SINGLE-LEVEL ANNEALED BONDS}

A series of experiments was performed to determine the pull strength variation with loop height of annealed single-level bonds. On a single substrate, groups of bond pairs were made at four loop heights with a nominal bond-to-bond spacing of $0.040 \mathrm{in}$. (1.0 mm). About half of these bonds were pulled to breaking in groups of ten at five different rates of pull. The remaining bonds were annealed at $505^{\circ} \mathrm{C}$ for $25 \mathrm{~min}$. and then groups of ten were pulled at each of the five rates. In agreement with previous measurements, the unannealed bonds did not exhibit any dependence of pull strength on rate of pull. Although there is an indication that the annealed bonds show some dependence of pull strength on rate of pull, the major problem encountered in the interpretation of the measurements on annealed bonds lies in the fact that there is considerable elongation of these bonds during pulling. The loop heights of annealed bonds at bond rupture are substantially larger than they are in the original unannealed state. In figure 16, pull strength is shown as a function of loop height at rupture for the unannealed and annealed bonds studies. The differences in loop height between the annealed bonds and the unannealed state at which all bonds were made is evident by comparing the loop height of each of the four unannealed points and their respective annealed points. As before, experimental data for unannealed bonds is in good agreement with that predicted by the resolution-of-forces analysis (solid curve) up to a loop height that corresponds to an h/d ratio of about $1 / 4$. No such agreement could be obtained for the data (solid points) obtained from annealed bonds. However, it can be seen that most of these points are for loop heights much larger than those for which agreement between experiment and theory is obtained for unannealed bonds. This lack of agreement has been attributed to the weakening effect of bond peel at large loop heights.

From the unannealed bond data, the percentage increase in pull strength required to bring the grand average of all pull strength group means at each loop height to coincidence with the theoretical curve was calculated. A linear relationship was obtained between percent correction in pull strength against measured pull strength. This was extrapolated to the larger loop height values appropriate to the annealed bonds. When the annealed bond data were corrected using this curve, the open points shown in figure 16 were obtained. It can be seen that these points appear to be in reasonable agreement with the theoretical curve shown $[10]$. 


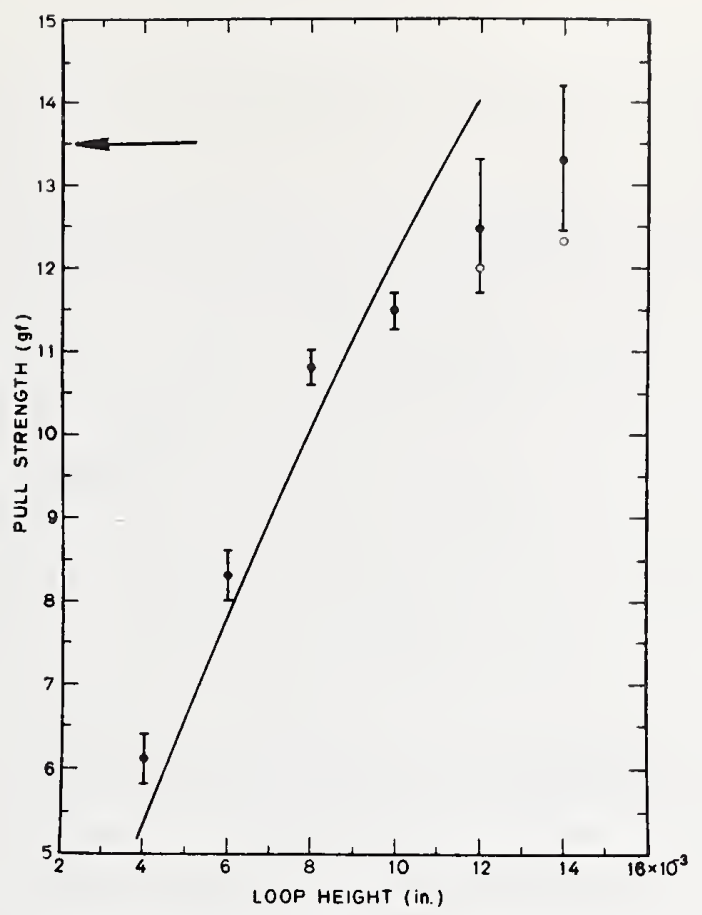

Figure 15. Pull strength of ribbon-wire bonds as a function of loop height. (The data points represent the mean for up to 10 bonds. Sol id circles include only bonds which ruptured at the heel; open circles include bonds which ruptured at the heel and which failed by lift off. Error bars represent one sample standard deviation. The solid curve is calculated from resolution-of-forces using the wire tensile strength indicated by the arrow.)

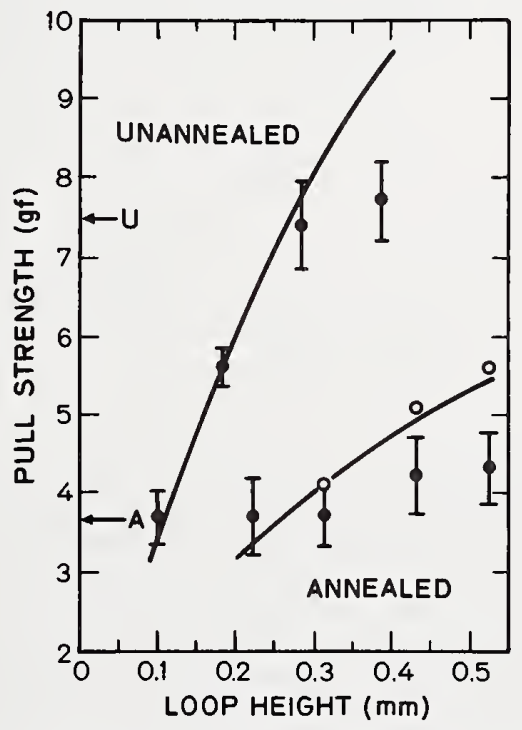

Figure 16. Pull strength of unannealed round-wire bonds and annealed round-wire bonds as a function of loop height. (Each solid data point represents the mean for a group of 10 bonds, the error bar represents one sample standard deviation. See text for a discussion of the open data points. The solid curves are calculated from resolution-of-forces using the wire tensile strength indicated by the arrows: $U$ - unannealed, A - annealed). 


\subsubsection{TWO-LEVEL BONDS}

For these loop height experiments, the two-level bonds had the following values of the variables held constant: $d=1.0 \mathrm{~mm}, \varepsilon=0.5, \phi=0, \mathrm{H}=0.25 \mathrm{~mm}$. Groups of 10 bonds were made at 7 different loop heights. This was done both for the first bond made on the high pad and for the first bond made on the low pad. In all cases failure occurred at the heel of the first bond. The measured pull strengths are plotted against loop height in figure 17 for both cases (solid points - first bond high, open points - first bond low). The plotted points represent the mean value of the 10 bond pulls and the error bars indicate one sample standard deviation on either side of the mean. The solid lines represent the values predicted by a resolution of the forces for each case. The agreement between the trend of the theoretical curve and that of the experimental points for the first bond made to the high pad appears to be good for loop heights less than about $0.3 \mathrm{~mm}$. For higher loops, the apparent pull strength is reduced as observed for both single level round and ribbon wire bonds (see $\sec$ 4.3.1).

The results for the case of the first bond made on the low pad generally show overall pull strengths less for a given loop height than those for the first bond made on the high pad. This is in agreement with the experimental measurement of the effects of angle $\beta$ (see fig 12) in which higher pull strengths were observed for negative values of the pull angle $\beta$ than for positive values [11].

This experiment was also carried out on bonds prepared on a different bonding machine. The results of this experiment are presented in figure 18 where the normalized pull strength is plotted against loop height. The results are in agreement with the above observations [5]. 


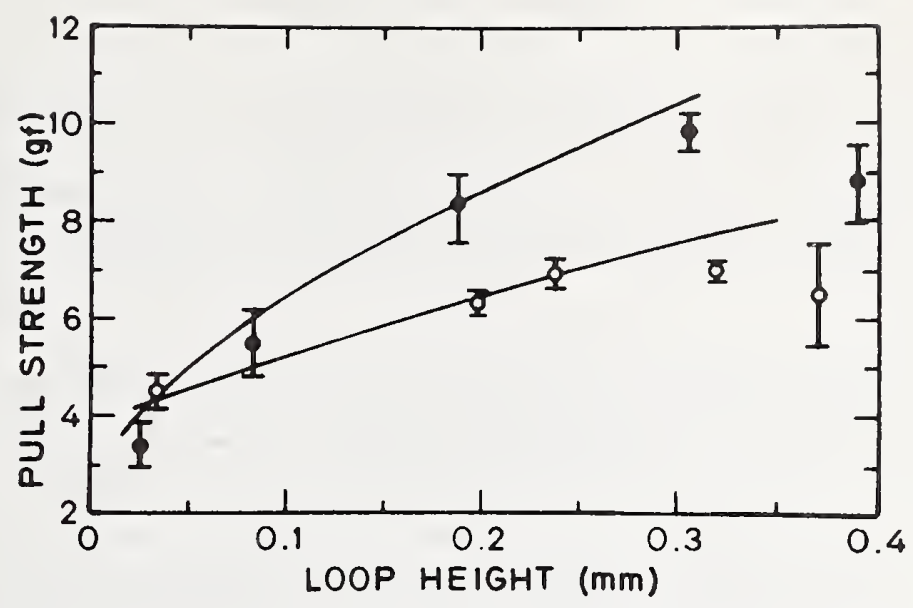

Figure 17. Measured pul1 strength of unannealed, round-wire, two-level bonds as a function of loop height above the high pad. (Solid points are for the first bond made on the high pad; open points are for the first bond made on the low pad. The data points represent the mean of 10 bonds, all of which ruptured at the heel of the first bond. Error bars indicate one sample standard deviation above and below the mean. The solid curves were calculated by resolution-of-forces.)

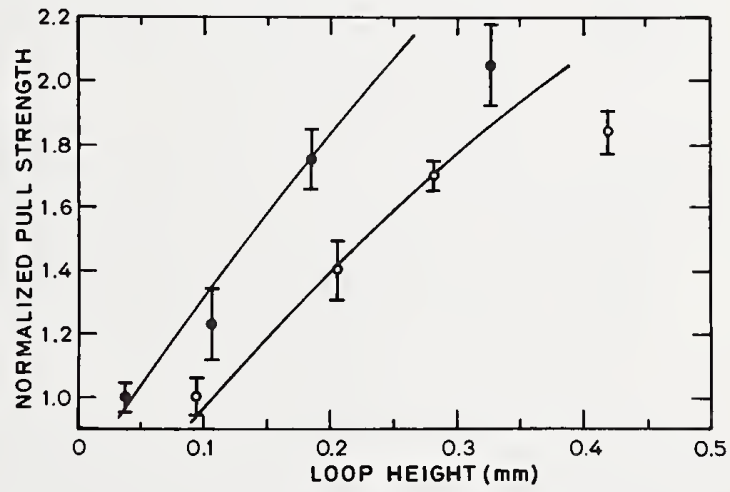

Figure 18. Normalized pull strength of unannealed, roundwire, two-level bonds as a function of loop height above the high pad. (The values are normalized to the mean pull strength at the lowest loop height. Solid points are for the first bond made on the high pad; open points are for the first bond made on the low pad. The data points represent the mean of 10 bonds, a11 of which ruptured at the heel of the first bond. Error bars indicate one sample standard deviation above and below the mean. The solid curves were calculated by resolution-offorces. The bonds used in this experiment were made on a different bonding machine from that used to provide the data for figure 17.) 
In this section, two of the variables which are not involved in the resolution-offorces calculation are considered. These variables are the rate of pull and the angle $\alpha$ (the angle between the direction of pull and the normal to the substrate in the plane perpendicular to both the substrate and the plane of the undisturbed bond loop).

\subsection{RATE OF PULL}

As the resolution-of-forces calculation is of a static nature, an investigation was undertaken to see if there were appreciable effects on the pull strength brought about by any transient effects induced by a rate dependent pull force. This is especially important as in industrial use of the pull test the wire is frequently pulled rapidly or jerked which may give rise to large transient effects. This is of potentially greater importance as the elongation of the wire increases, since the effects of larger transients may be accentuated by greater wire elongation.

In a first series of experiments, a group of 10 unannealed bonds was pulled to destruction at 11 different pull rates ranging from $1.0 \mathrm{gf} / \mathrm{s}(9.8 \mathrm{mN} / \mathrm{s})$ to $12.5 \mathrm{gf} / \mathrm{s}(122 \mathrm{mN} / \mathrm{s})$. The results of this experiment are presented in figure 19 where the mean pull strength (with the 95 percent confidence intervals for the mean) is plotted against the pull rate. The slope of the curve was determined to be essentially zero. It was, therefore, concluded that the pull rate has no significant effect on the bond pull strength for the range of pull rate between 1.0 and $12.5 \mathrm{gf} / \mathrm{s}$ ( 9.8 to $122 \mathrm{mN} / \mathrm{s}$ ) [12].

In a second series of experiments, the investigation of the effect of the rate of pull on pull strength was extended to cover rates of 1.0 and $77 \mathrm{gf} / \mathrm{s}$ ( 9.8 and $764 \mathrm{mN} / \mathrm{s}$ ). As with the first series of experiments, all bonds were made with the same bonding schedule in sequence by one operator. Also, this schedule was set up such that the failure mode was breakage at the heel of the first bond. Groups of 60 bonds each were then pulled at rates of 1.0 and $77 \mathrm{gf} / \mathrm{s}(9.8$ and $764 \mathrm{mN} / \mathrm{s})$ resulting in times to pull a bond of approximately 9 and $0.12 \mathrm{~s}$. The date obtained indicated that there was no statistically significant difference in the measured pull strengths for either pull rate from those in figure $19 .{ }^{\dagger}$

The above experiments were performed on single-level unannealed bonds where heel breakage was the failure mode. For bonds which fail by peeling or lift-off, it is assumed that the rate of pull would have a large effect on the measured pull strength since peel failure appears to be rate sensitive. However, it is very difficult to show this statistically as a procedure to make bonds reproducibly that will fail by peeling has not been found. Attempts have resulted in pull strengths which have greater variations from bondto-bond, at a given pull rate, than between groups pulled at different rates. Therefore, a pull-rate experiment as described was not performed for bonds which fail by peel. However, it appears that the nature of the failure mode may affect comparisons of pull strengths.

Tecent work (Kessler, H. K., in Semiconductor Measurement Technology: Progress Report, Bullis, W. M., Ed., NBS Special Publication 400-25 - to appear) indicates that the pull strength of gold wire is also pull-rate independent. 


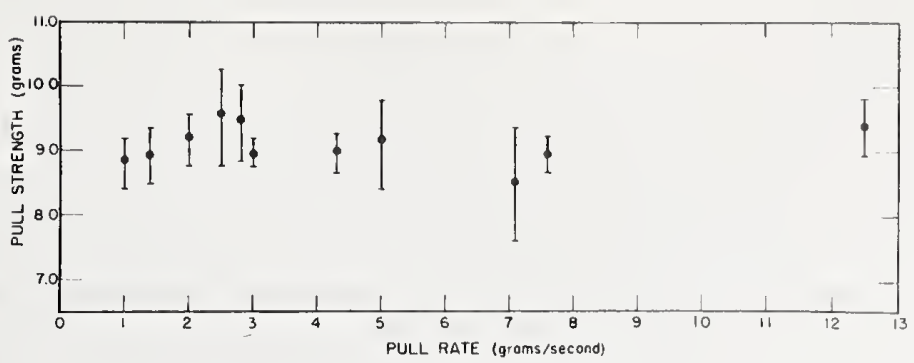

Figure 19. Measured bond pull strength as a function of pull rate. (The error bars represent the 95 percent confidence intervals for the mean.)

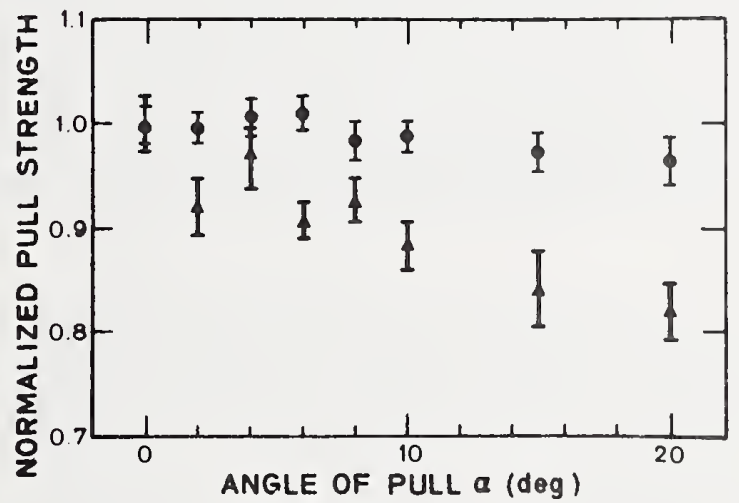

Figure 20. Normalized pull strength as a function of pull angle, $\alpha$, for round-wire bonds with small (•) and Targe ( $\Delta$ ) deformation. (Error bars represent the 95 percent confidence interval for the mean. The values are normalized to the mean put1 strength at each deformation at $\alpha=0$ deg.) 
and rates of pull [13].

\subsection{ANGLE $\propto$}

\subsubsection{NTRODUCTION}

The resolution-of-forces calculation as presented in Section 2 and the Appendix of this report is essentially a two-dimensional calculation. That is, only those forces operative in the plane of the bond 1oop are considered. A series of experiments was undertaken to investigate the effects of pulling the bond in a direction not in this plane on the measured pull strength. The angle $\alpha$ is defined as that between the direction of pull and the normal to the substrate in the plane perpendicular to both the substrate and the plane of the undisturbed bond loop. Since the principal effect of pulling at a finite value of $\alpha$ is to rotate the plane of the bond loop, the ratio of the force of pull and the force exerted along the wire is the same for all values of $\alpha$. This would lead one to conclude that no great dependence on the measured pull strength on $\alpha$ would be expected. However, the rotation of the plane of the bond loop does not include rotation of the bond heel. This tends to put the bond heel under an anisotropic stress with respect to the line between the bonds. This anisotropic stress may be expected to be accentuated by greater bond deformation. This reasoning points to the possibility of decreased measured bond pull strength with increased $\alpha$. This decrease is expected to be most pronounced with a large deformation.

\section{2 .2 SINGLE-LEVEL BONDS}

Single-level round-wire bonds were made on three metallized substrates with 0.001-in. $(25-\mu \mathrm{m})$ diameter aluminum ( $1 \%$ silicon) wire and a bond-to-bond spacing of 0.04 in. (1.0 mm). All the bonds on a particular substrate were made with the same power setting, but different power settings were used in making the bonds on different substrates to obtain bonds with different degrees of bond deformation. On each substrate, about 35 bonds were pulled at the midpoint of the loop for eight values of $\alpha$ from 0 to $20 \mathrm{deg}$. The pull angle $\phi$, in the plane of the bond 1oop, was $0 \mathrm{deg}$. For each group, the mean pull strength and the 95 percent confidence interval for the mean was determined; the measured pull strengths of bonds that did not break at the heel were excluded from the calculations. The pull strengths were then normalized to the mean value obtained at $\alpha=0 \mathrm{deg}$. The results for bonds on two substrates, with small deformation ( 1.25 to 1.50 wire diameters) and large deformation (2.25 to 2.50 wire diameters), are shown in figure 20. The zero degree value for pull strength of the bonds with large bond deformation was approximately half that of the bonds with small bond deformation. Bonds made on the third substrate had excessively large bond deformation but yielded results essentially the same as those observed for bonds with large bond deformation.

The results show that as $\alpha$ increases, the measured pull strength decreases. This appears to be a result of the twisting or tearing of the bond heel as the wire is pulled out of the plane normal to the substrate plane. These results show that, although the value of angle $\alpha$ has little effect on the measured pull strength of bonds with small to moderate 
bond deformation, the effect is more pronounced for the bonds with greater bond deformation. Although it was not experimentally demonstrated, it is hypothesized that if the failure mode were by peel significantly lower pull strengths would occur at large values of $\alpha$. This reasoning follows that presented in the introductory material. For peel failure at $\alpha=0$, the force tending to lift the bond acts uniformly over a large area. For $\alpha \neq 0$, the force tends to be concentrated on one side of the bond and hence initiates lift-off at a lower pull force. It should be possible to control the position of the pulling hook so that the angle $\alpha$ is less than $10 \mathrm{deg}$ by visual inspection, but more precise positioning may be required for bonds with large deformation [14].

\subsubsection{TWO-LEVEL BONDS}

The experiments on the effects of the angle $\alpha$ on the pull strength were carried out for small deformation two-level bonds in which the first bond was made on the high pad. Bond pairs were made on two different bonding machines designated as machine $A$ and machine $B$. The measured pull strength, normalized to its value for $\alpha=0$, is presented as a function for $\alpha$ for both cases in figure 21. As with the analysis of the single leve1 data, on $1 y$ those failures due to rupture at the first bond were included in the data. The curves in figure 21 show roughly the same general trends in both cases except for differences in the standard deviations. The results are in general agreement with the measurements of pull strength made on single-level bond pairs of small deformation [5].

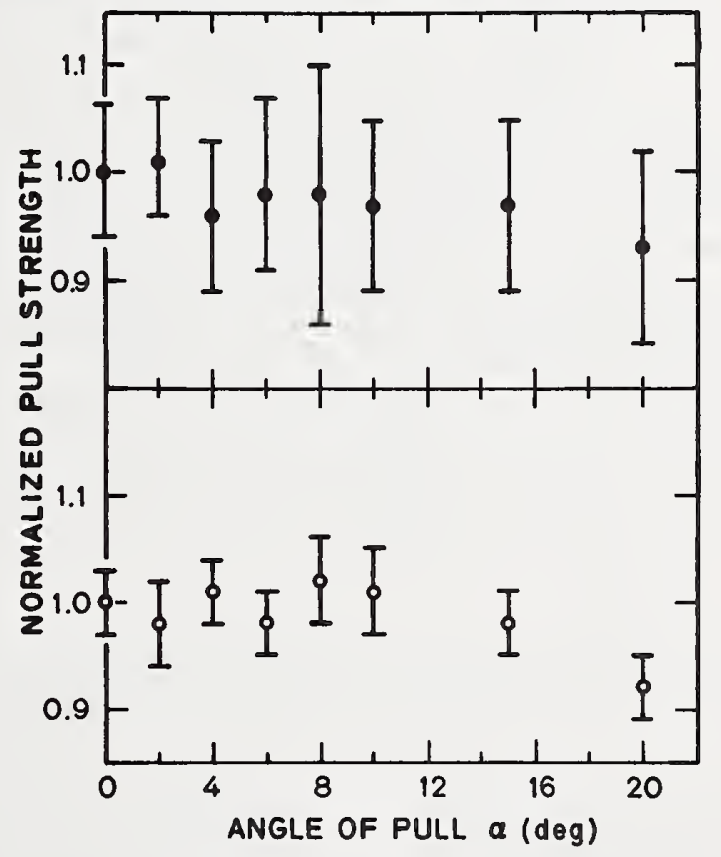

Figure 21. Measured pull strength as a function of angle of pul1, $\alpha$, for two-level bond pairs. (The values are normalized to the mean pull strength at $\alpha=0$ deg. Solid points are for bond pairs made on bonding machine $A$. Open points are for bond pairs made on machine B. Error bars represent one sample standard deviation above and below the mean.) 


\section{SENSITIVITY CALCULATION}

The sensitivity of the measured pull strength of wire bonds to variations in experimental conditions was analyzed for the case, appropriate to unannealed aluminum ultrasonic bonds, in which measured pull strengths are in agreement with those predicted by resolutionof-forces. The normalized variation in pull strengths of the bond to the terminal, $\Delta \mathrm{F}(\mathrm{t})$, and of the bond to the pad on the die, $\Delta F(d)$, were studied as a function of the position of the pulling hook, $\varepsilon$; the loop height above the terminal post, $h$; the height of the terminal post above the die, $\mathrm{H}$; the bond-to-bond spacing, $\mathrm{d}$; and the pull angle with respect to the normal to the substrate, $\phi$.

To illustrate the application of this analysis, computations were made for a transistor in a TO-18 can. The TO-18 configuration was used as bond geometry variables were given in manufacturer's specifications. Each of the five quantities was varied about its nominal value while the other four quantities were held constand, and $\Delta F(t)$ and $\Delta F(d)$ were computed. The results are summarized in table 2 ; the quantities are listed in order of decreasing effect on the measured pull strength. Except for variation of $\phi$, the variation is expressed in percent of the nominal value.

It can be seen that, for the device described, the pull angle $\phi$ has the greatest effect on $\Delta \mathrm{F}(\mathrm{t})$ and $\Delta \mathrm{F}(\mathrm{d})$. Of the five parameters, the pull test operator controls only $\phi$ and $\varepsilon$; the reproducibility of $\mathrm{h}$ and $\mathrm{d}$ is dependent on the bonding machine, and that of $\mathrm{H}$ is dependent on the header lot and die thickness. In making wire bonds in this laboratory, $h$ and $d$ can be reproduced to \pm 3.0 and \pm 3.8 percent (one standard deviation), respectively. Typical manufacturer's specifications for To can-type headers suggest that variations in post height of \pm 30 percent may be expected. An estimate of the overall variation to be expected in determining pull strength was obtained by calculating values of $\Delta F(t)$ and $\Delta F(d)$ as a function of $\phi$ for two cases for the sample device. In one case each of the other four quantities assumed its smallest value, in the other each assumed its largest value. The results for these simulations of the application of the pull test in an industrial environment, shown in figure 22 indicate that, for the heel break (tensile) failure mode, variations in $\phi$ of 10 deg can produce differences in pull strength from the zero degree case of as much as 30 percent [15]. 
Table 2 - Calculated Dependence of $\Delta F(t)$ and $\Delta F(d)$ on Pull Test Conditions for a T0-18 Transistor

\begin{tabular}{ccccccc}
\hline Quantity & Change & $\Delta \mathrm{F}(\mathrm{t})$ & $\Delta \mathrm{F}(\mathrm{d})$ & Change & $\Delta \mathrm{F}(\mathrm{t})$ & $\Delta \mathrm{F}(\mathrm{d})$ \\
\hline \multirow{6}{*}{$\phi$} & $+10 \mathrm{deg}$ & $-11 \%$ & $+14 \%$ & $+20 \mathrm{deg}$ & $-19 \%$ & $+37 \%$ \\
& $-10 \mathrm{deg}$ & $+20 \%$ & $-8 \%$ & $-20 \mathrm{deg}$ & +50 & -13 \\
$\mathrm{~d}$ & $+10 \%$ & $-7 \%$ & -6 & $+20 \%$ & -13 & -11 \\
& $-10 \%$ & $+8 \%$ & +6 & $-20 \%$ & +16 & +13 \\
$\mathrm{~h}$ & $+10 \%$ & $+5 \%$ & +5 & $+20 \%$ & +11 & +10 \\
& $-10 \%$ & -5 & -5 & $-20 \%$ & -12 & -10 \\
\multirow{2}{*}{$\varepsilon$} & $+10 \%$ & +4 & -3 & $+20 \%$ & +9 & -5 \\
& $-10 \%$ & -3 & +4 & $-20 \%$ & -6 & +9 \\
$H$ & $+10 \%$ & +2 & +0.5 & $+20 \%$ & +3 & +1.0 \\
& $-10 \%$ & -2 & -0.5 & $-20 \%$ & -3 & -1.0 \\
\hline
\end{tabular}

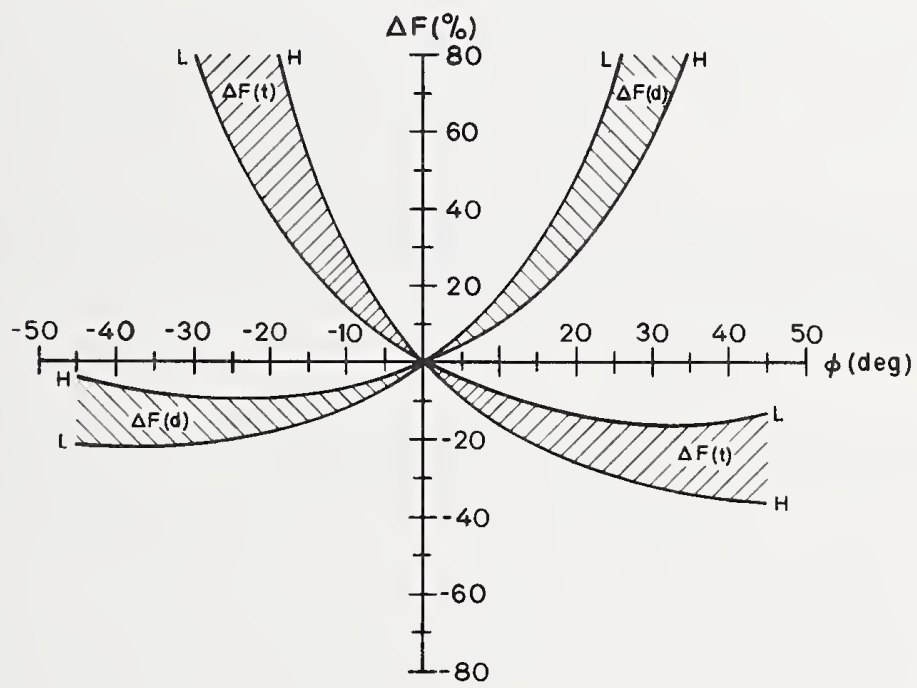

Figure 22. Normalized variation in calculated pull strength for the terminal bond, $\Delta F(t)$, and die bond, $\Delta F(d)$ as a function of pull angle $\phi$.

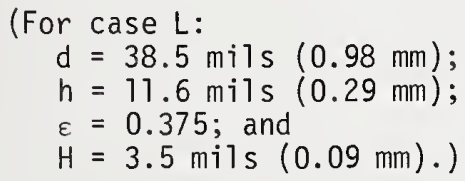

(For case $\mathrm{H}$ :

$\mathrm{d}=41.5 \mathrm{mi1s}(1.05 \mathrm{~mm})$;

$\mathrm{h}=12.4 \mathrm{mils}(0.31 \mathrm{~mm})$;

$\varepsilon=0.625 ;$ and

$H=6.5 \mathrm{mils}(0.17 \mathrm{~mm})$. 


\section{SUMMARY}

It has been shown for $0.001-i n$. (25- $\mu \mathrm{m})$ diameter ultrasonically bonded aluminum ( $1 \%$ silicon) wire that the variations in measured pull strength as functions of bond loop height and position of the pulling hook are in agreement with those predicted by resolution-offorces for single- and two-level unannealed wire bond pairs provided that the ratio of the loop height, $h$, to bond-to-bond spacing, $d$, is less than about $1 / 3$. For annealed bonds, agreement was not found. This was attributed to the fact that the stretching of the wire loop during pulling always resulted in $h / d$ values greater than $1 / 3$. It should be noted that these conclusions are drawn from those experiments where heel breakage (tensile failure) is the exclusive failure mode.

The decrease in measured pull strength with increasing pull angle $\alpha$, in both singleand two-level bond pairs, more pronounced on bonds with large deformation, appears to be a result of the twisting or tearing of the bond heel as the wire is pulled out of the plane normal to the substrate plane. In the series of measurements on the effects on pull strength of varying the pull angle $\beta$, for both single- and two-level unannealed wire bonds, a large decrease in pull strength was observed as $\beta$ went from -45 to $0 \mathrm{deg}$; as $\beta$ went from 0 to +45 deg, the decrease was much less marked. This is consistent with the facts that the second bond is stronger than the first bond and therefore the measured pull strength is lower when the larger component of force is applied to the first bond, and higher when applied to the second bond.

Examples of the practical applications of the work reported here are to be found in the sensitivity calculation; the bond pull specifications for large-diameter wire; and a nondestructive bond pull test. 
1. Schafft, H.A., Testing and Fabrication of Wire-Bond Electrical Connections -- A Comprehensive Survey, NBS Technical Note 726 (Sept. 1972).

2. Harman, G.G., Semiconductor Measurement Technology: Microelectronic Ultrasonic Bonding, NBS Special Publication 400-2 (Jan. 1974).

3. Schafft, H.A. in Methods of Measurement for Semiconductor Materials, Process Control, and Devices, Bullis, W.M., Ed., NBS Technical Note 555 (Sept. 1970), pp. 31-35. (See a1so Ref 1, pp. 57-73)

4. Leedy, K.0., Madello, J.K., and Krawczyk, J. in Methods of Measurement for Semiconductor Materials, Process Control, and Devices, Bullis, W.M., Ed., NBS Technical Note 527 (May 1970), pp. 39-41.

5. Sher, A.H., Main, C.A., and Leedy, K.O. in Methods of Measurement for Semiconductor Materials, Process Control, and Devices, Bullis, W.M., Ed., NBS Technical Note 788 (Aug. 1973), pp. 30-34.

6. Leedy, K.O., and Main, C.A. in Methods of Measurement for Semiconductor Materials, Process Control, and Devices, Bullis, W.M., Ed., NBS Technical Note 727 (June 1972), pp. 38-43.

7. Leedy, K.O. and Main, C.A. in Methods of Measurement for Semiconductor Materials, Process Control, and Devices, Bullis, W.M., Ed., NBS Technical Note 717 (April 1972), pp. 28-29.

8. Sher, A.H. in Methods of Measurement for Semiconductor Materials, Process Control, and Devices, Bullis, W.M., Ed., NBS Technical Note 743 (Dec. 1972), p. 29.

9. Kessler, H.K. and Sher, A.H. in Methods of Measurement for Semiconductor Materials, Process Control, and Devices, Bullis, W.M., Ed., NBS Technical Note 743 (Dec. 1972), pp. 29-30.

10. Sher, A.H. and Main, C.A. in Methods of Measurement for Semiconductor Materials, Process Control, and Devices, Bullis, W.M., Ed., NBS Technical Note 773 (June 1973), pp. 26-27.

11. Leedy, K.O., Main, C.A., and Sher, A.H. in Methods of Measurement for Semiconductor Materials, Process Control, and Devices, Bullis, W.M., Ed., NBS Technical Note 754 (March 1973), pp. 21-23.

12. Leedy, K.O. and Ricks, D.R. in Methods of Measurement for Semiconductor Materials, Process Control and Devices, Bullis, W.M., Ed., NBS Technical Note 560 (Nov. 1970), pp. 30-31.

13. Leedy, K.O. and Main, C.A. in Methods of Measurement for Semiconductor Materials, Process Control, and Devices, Bullis, W.M., Ed., NBS Technical Note 592 (Aug. 1971), p. 35.

14. Leedy, K.O., Sher, A.H., and Main, C.A. in Methods of Measurement for Semiconductor Materials, Process Control, and Devices, Bullis, W.M., Ed., NBS Technical Note 743 (Dec. 1972), pp. 27-28. 
15. Sher, A.H., in Methods of Measurement for Semiconductor Materials, Process Control, and Devices, Bullis, W.M., Ed., NBS Technical Note 806 (Nov. 1973), pp. 28-30.

16. Harman, G.G. in Methods of Measurement for Semiconductor Materials, Process Control, and Devices, Bullis, W.M., Ed., NBS Technical Note 806 (Nov. 1973), pp. 35-36.

17. Harman, G.G., A Metallurgical Basis for the Non-Destructive Wire-Bond Pull Test, 12th Annal Proceedings, Reliability Physics 1974, Las Vegas, Nevada, April 2-4, IEEE Catalog No. 74CH0839-1 PHY. pp. 205-210.

18. Ang, C.Y., Eisenberg, P.H., and Matraw, H.C., Physics of Control of Electronic Devices, Proc. 1969 Annual Symposizm on Reliability, Chicago, Illinois, January 1969, pp. 73-85.

19. Slemmons, J.W., The Microworld of Joining Technology, Proc. American Welding Society 50th Annual Meeting, Philadelphia, Pennsylvania, April 1969, pp. 22-27, 35, 56, 72.

20. Polcari, S.M., and Bowe, J.J., Evaluation of Non-Destructive Tensile Testing, DOT-TSCNASA-71-10 (1971). (Available from National Technical Information Service, Springfield, Virginia 22151, Accession No. N71-37516.)

21. Bertin, A.P., Development of Microcircuit Bond-Pull Screening Techniques, Rome Air Development Center - Technical Report-73-123 (April 1973).

22. Harman, G.G., Metallurgical Failure Modes of Wire Bonds, 12th Annual Proceedings, Reliability Physics 1974, Las Vegas, Nevada, April 2-4, IEEE Catalog №. 74CH0839-1 PHY., pp. 131-141. 
This appendix is intended to provide some of the details necessary to obtain eqs (1) through (8) of Section 2 of this report. Referring to figure 1, the vector diagram of figure Al may be constructed. Considering the applied pulling force at an infinitesimal increment in force before rupture takes place, balancing of the forces along the $x$ direction and the $\mathrm{y}$ direction requires that

$$
F_{w t} \cos \theta_{t}=F \sin \phi+F_{w d} \cos \theta_{d},
$$

and

$$
F \cos \phi=F_{w t} \sin \theta_{t}+F_{w d} \sin \theta_{d},
$$

respectively.

Solving eq (A2) for $\mathrm{F}_{\mathrm{wt}}$, one obtains

$$
F_{w t}=\frac{F \cos \phi-F_{w d} \sin \theta_{d}}{\sin \theta_{t}}
$$

Substituting eq (A3) into eq (A1) and solving for $F_{\text {wd }}$, one obtains eq (1):

$$
\begin{aligned}
F_{w d} & =F\left(\frac{\cos \phi \operatorname{ctn} \theta_{t}-\sin \phi}{\sin \theta_{d} \operatorname{ctn} \theta_{t}+\cos \theta_{d}}\right) \\
& =F \frac{\cos \left(\theta_{t}+\phi\right)}{\sin \left(\theta_{d}+\theta_{t}\right)} .
\end{aligned}
$$

Substituting eq (A4) into eq (A2) and solving for $F_{w t}$, one obtains eq (2):

$$
F_{w t}=F \frac{\cos \left(\theta_{d}-\phi\right)}{\sin \left(\theta_{t}+\phi_{d}\right)} .
$$




$$
\begin{aligned}
& \sin \theta_{d}=\frac{(h+H)}{\left[(h+H)^{2}+[(1-\varepsilon) d]^{2}\right]^{\frac{1}{2}}} \cdot \\
& \cos \theta_{d}=\frac{(1-\varepsilon) d}{\left[(h+H)^{2}+[(1-\varepsilon) d]^{2}\right]^{\frac{1}{2}}} \\
& \sin \theta_{t}=\frac{h}{\left[h^{2}+(\varepsilon d)^{2}\right]^{\frac{1}{2}}} \\
& \cos \theta_{t}=\frac{\varepsilon d}{\left[h^{2}+(\varepsilon d)^{2}\right]^{\frac{1}{2}}} \cdot
\end{aligned}
$$

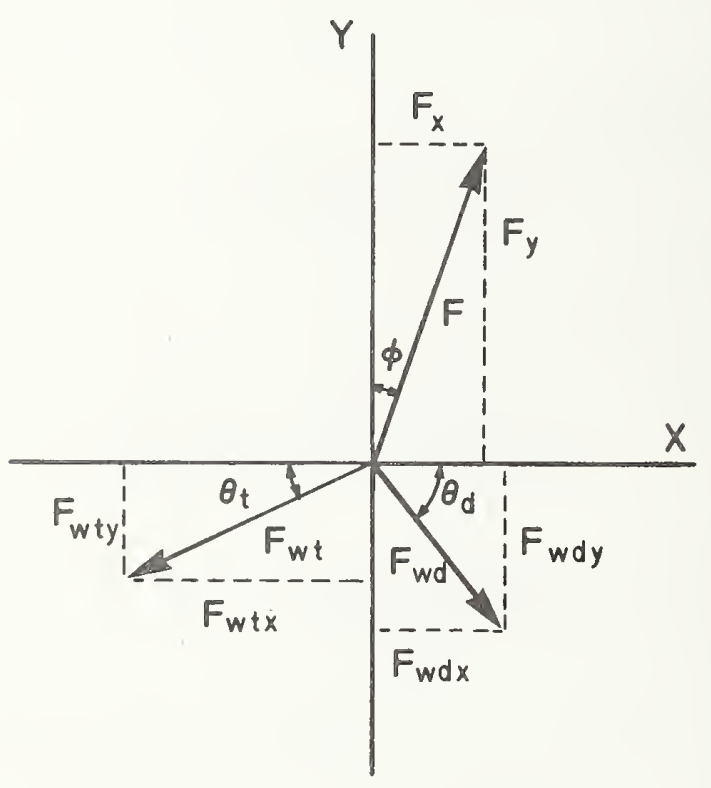

Figure A1. Vector diagram for resolution-of-forces operative in bonded system during application of pulling force. (The following relations are used in obtaining Eqs. (AI) and (A2).)

$$
\begin{array}{ll}
F_{x}=F \sin \phi & F_{y}=F \cos \phi \\
F_{w t x}=F_{w t} \cos \theta_{t} & F_{w t y}=F_{w t} \sin \theta_{t} \\
F_{w d x}=F_{w d} \cos \theta_{d} & F_{w d y}=F_{w d} \sin \theta_{d}
\end{array}
$$


This appendix contains several programs which may be used to calculate $F$ wt and $F$ wd from the resolution-of-forces calculation (See eqs (4) and (5)). These programs are in HP-65 language, Basic, and Fortran.

With the HP-65 program, the key entries of table Bl are entered into the calculator and put on magnetic cards according to the instructions given in the owner's manual. The program is then permanently entered on the magnetic cards.

To perform the calculation the following instructions are to be used.

Enter the program. Clear the memory registers if they are full. Then, enter each of the six variables in the memory indicated below. (There is no need to clear the stack after each entry.)

\begin{tabular}{cc} 
Key Entr \\
\hline ST0 & 1 \\
STO & 2 \\
STO & 3 \\
STO & 4 \\
STO & 5 \\
STO & 6
\end{tabular}

\section{Stored Variables}

h

$\mathrm{H}$

d

$\varepsilon$

F

$\phi$

If any variable is zero, simply ignore that particular memory. Then press either A or B to obtain the desired result (either $F_{w t}$ or $F_{\text {wd }}$ ).

Any or all of the variables may be changed by simply entering the new values in the appropriate memories.

In the case of the angle $\phi$, which is normally expressed in degrees, this may be entered as either positive or negative depending upon the actual physical situation.

The values of $\mathrm{h}, \mathrm{H}$, and $\mathrm{d}$ may be entered in either English or metric units so long as they are consistent.

The value of $F$ may be any set of units and need not be consistent with the units of h, $H$, and $d$. The forces $F_{w t}$ and $F_{\text {wd }}$ will, of course, have the units of $F .{ }^{\dagger}$

The remaining programs which may be used to calculate $F_{w t}$ and $F_{\text {wd }}$ are given in Basic and Fortran. The programs have all the necessary information to allow for rapid computation. It should be noted that step 990 of the Basic program and the corresponding step of the Fortran V program convert the pull angle $\phi$ from degrees to radians. This is required by the fact that both Basic and Fortran read angles in radians. However, the readout of the angle is given in degrees. If a particular machine reads angles in degrees, simply set A2=A1. $+\dagger$

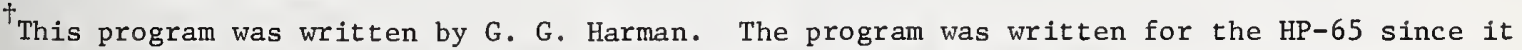
was the only programmable pocket calculator available at the time. Other programmable pocket calculation may also be used for the computation.

The Basic program, written with the assistance of W. J. Keery, is an adaptation of one used by A. H. Sher to perform the sensitivity calculation (ref 15). The Fortran program was written with the assistance of T. F. Leedy. 
Table B1

HP-65 Program for Resolution-of-Forces Calculation

SWITCH TO W PRGM PRESS I PRGM TO CLEARMEMORY.

\begin{tabular}{|c|c|c|c|c|c|c|}
\hline $\begin{array}{c}\text { KEY } \\
\text { ENTRY }\end{array}$ & $\begin{array}{l}\text { CODE } \\
\text { SHOWN }\end{array}$ & COMMENTS & $\begin{array}{c}\text { KEY } \\
\text { ENTRY }\end{array}$ & $\begin{array}{c}\text { CODE } \\
\text { SHOWN } \\
\end{array}$ & COMMENTS & REGISTERS \\
\hline LBL & 23 & & $\div$ & 81 & & \multirow[t]{3}{*}{$R_{1}, \mathrm{~h}$} \\
\hline $\mathrm{A}$ & 11 & & \begin{tabular}{|l|} 
RCL 5 \\
\end{tabular} & $34 \quad 05$ & & \\
\hline$E$ & 31 & & $x$ & 71 & & \\
\hline STK & 42 & & RTN & 24 & & \multirow[t]{3}{*}{$\mathrm{R}_{2}$} \\
\hline $\mathrm{RCL} \quad 1$ & $\begin{array}{ll}34 & 01\end{array}$ & & LBL & 23 & & \\
\hline $\mathrm{RCL} 2$ & $\begin{array}{ll}34 & 02\end{array}$ & & $B$ & 12 & & \\
\hline+ & 61 & & $f$ & 31 & & \multirow[t]{3}{*}{$R_{3} \quad d$} \\
\hline$P C J \quad 3$ & $\begin{array}{ll}34 & 03\end{array}$ & & STK & 42 & & \\
\hline$\div$ & 81 & & RCI, 6 & 3406 & & \\
\hline RCL 6 & 3406 & & $\mathrm{f}$ & 31 & & \multirow[t]{3}{*}{$R_{4} \quad \varepsilon$} \\
\hline $\mathrm{f}$ & 31 & & $\cos$ & 05 & & \\
\hline SIN & 04 & & RCL 4 & $34 \quad 04$ & & \\
\hline $\mathrm{x}$ & 71 & & $\mathrm{x}$ & 71 & & \multirow[t]{3}{*}{$R_{5} \ldots$} \\
\hline RCL 6 & 3406 & & RCL 6 & $34 \quad 06$ & & \\
\hline $\mathrm{f}$ & 31 & & $\mathrm{f}$ & 31 & & \\
\hline $\cos$ & 05 & & SIN & 04 & & \multirow[t]{3}{*}{$R_{6} \quad \phi$} \\
\hline 1 & 01 & & RCL 1 & 3401 & & \\
\hline$\uparrow$ & 41 & & \begin{tabular}{|l|} 
RCL 3 \\
\end{tabular} & 3403 & & \\
\hline RCL 4 & $34 \quad 04$ & & $\div$ & 81 & & \multirow{3}{*}{$R_{7} \frac{\text { used for }}{\text { inter- }}$} \\
\hline- & 51 & & $x$ & 71 & & \\
\hline$x$ & 71 & & - & 51 & & \\
\hline+ & 61 & & \begin{tabular}{|l|} 
RCL 2 \\
\end{tabular} & $34 \quad 02$ & & \multirow[t]{2}{*}{$R_{8}$ storage } \\
\hline STO 7 & $\begin{array}{ll}33 & 07\end{array}$ & & RCL 1 & $34 \quad 01$ & & \\
\hline$C L \mathrm{x}$ & 44 & & $\div$ & 81 & & \\
\hline RCL 4 & $34 \quad 04$ & & 1 & 01 & & \multirow{3}{*}{$R_{9}$} \\
\hline $\mathrm{RCL} 3$ & $\begin{array}{ll}34 & 03\end{array}$ & & + & 61 & & \\
\hline$x$ & 71 & & $x$ & 71 & & \\
\hline RCL 1 & $\begin{array}{ll}34 & 01 \\
\end{array}$ & & STO 7 & 3307 & & \multirow{3}{*}{$\begin{array}{l}\text { LABELS } \\
A \frac{x}{B}+x\end{array}$} \\
\hline$\div$ & 81 & & $\begin{array}{|ll|} & \mathrm{CL} \\
\end{array}$ & 44 & & \\
\hline $\mathrm{f}^{-1}$ & 32 & & $\begin{array}{|ll|}\mathrm{RCL} & 3 \\
\end{array}$ & $34 \quad 03$ & & \\
\hline$\sqrt{x}$ & 09 & & 1 & 01 & & \multirow{4}{*}{$\begin{array}{l}C \\
D \\
E \\
0\end{array}$} \\
\hline 1 & 01 & & RCL 4 & $34 \quad 04$ & & \\
\hline+ & 61 & & - & 51 & & \\
\hline $\mathrm{f}$ & 31 & & $x$ & 71 & & \\
\hline$\sqrt{x}$ & 09 & & RCL 1 & $34 \quad 01$ & & \multirow{4}{*}{$\begin{array}{l}1 \\
2 \\
3 \\
4\end{array}$} \\
\hline RCL 7 & $\begin{array}{ll}34 & 07 \\
\end{array}$ & & \begin{tabular}{|l|} 
RCL 2 \\
\end{tabular} & $34 \quad 02$ & & \\
\hline$x$ & 71 & & + & 61 & & \\
\hline STO 7 & $\begin{array}{ll}33 & 07\end{array}$ & & $\div$ & 81 & & \\
\hline $\mathrm{CL} \mathrm{x}$ & 44 & & $f^{-1}$ & 32 & & \multirow{2}{*}{$\begin{array}{l}5 \\
6 \\
\end{array}$} \\
\hline LBL & 23 & & $\sqrt{x}$ & 09 & & \\
\hline 8 & 08 & step 40 to 54 & 1 & 01 & & \multirow{4}{*}{ 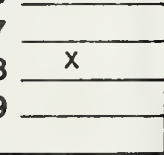 } \\
\hline RCL 2 & $\begin{array}{ll}34 & 02\end{array}$ & is a subroutine & + & 61 & & \\
\hline RCL 4 & $\begin{array}{ll}34 & 04\end{array}$ & used in both & $\mathrm{f}$ & 31 & & \\
\hline$x$ & 71 & $F_{w t}+F_{w d}$ & $\sqrt{\sqrt{x}}$ & 09 & & \\
\hline RCL 1 & 3401 & & RCL 7 & $34 \quad 07$ & & \multirow{4}{*}{ FLAGS } \\
\hline$\div$ & 81 & & $\mathrm{x}$ & 71 & & \\
\hline 1 & 01 & & STO 7 & 3307 & & \\
\hline+ & 61 & & CL $\mathrm{x}$ & 44 & & \\
\hline RCL 7 & $\begin{array}{ll}34 & 07\end{array}$ & & $g+0$ & 22 & & \multirow{2}{*}{2} \\
\hline $9 x+2 y$ & $\begin{array}{ll}35 & 07\end{array}$ & & 8 & 08 & & \\
\hline
\end{tabular}


10 PRINT "DO YOU WANT ALL THE INTRODUCTORY COMMENTS? (YES=1, NO=2)"

20 INPUT $N$

30 ON N GO TO 40,380

40 PRINT

50 PRINT "* * * * * * * RESOLUTION OF FORCES CALCULATION *******"

60 PRINT " * * * * * * * DESTRUCTIVE BOND PULL TEST * *******"

70 PRINT

80 PRINT "THIS PROgRAM CALCULATES THE FORCES ON THE WIRE AT THE"

90 PRINT "TERMINAL AND AT THE DIE FROM THE BOND GEOMETRY AND THE"

100 PRINT "PULL. STRENGT H"

110 PRINT

120 PRINT "B IS THE HEIGHT, AT RUPTURE, OF THE WIRE SPAN (AT THE "

130 PRINT " POINT OF PULL) ABOVE THE TERMINAL"

140 PRINT

150 PRINT "H IS THE HEIGHT OF THE TERMINAL RELATIVE TO THE DIE SURFACE"

160 PRINT

170 PRINT "D IS THE BOND-TO-BOND SPACING"

180 PRINT

190 PRINT "E IS THE DIMENSIONLESS FRACTIONAL HORIZONTAL DISTANCE BETWEEN"

200 PRINT" "THE TERMINAL BOND AND THE POINT OF APPLICATION OF THE "

210 PRINT " FORCE"

220 PRINT

230 PRINT "F IS THE PULL STRENGTH"

240 PRINT

250 PRINT "A IS THE PULL ANGLE AND IS EXPRESSED IN UNITS OF DEGREES"

260 PRINT

270 PRINT "T1 IS THE FORCE ON THE WIRE AT THE TERMINAL. FWT"

280 PRINT

290 PRINT "T2 IS THE FORCE ON THE WIRE AT THE DIE, FWD"

300 PRINT

310 PRINT "THE VALUES OF B, H, AND D MAY BE EXPRESSED IN EITHER"

320 PRINT "ENGLISH OR METRIC SO LONG AS THEY ARE CONSISTENT"

330 PRINT

340 PRINT "THE VALUE OF F MAY BE IN ANY SET OF UNITS AND NEED NOT BE"

350 PRINT "CONSISTENT WITH THE UNITS OF B, H. AND D"

360 PRINT

370 PRINT "THE FORCES T1 AND T2 WILL, OF COURSE, HAVE THE UNITS OF F"

380 PRINT

390 PRINT

400 PRINT "ENTER B, H, D, E, F,A"

410 INPUT $B, H, D, E, F, A$

420 PRINT

430 PRINT "SPECIFY PARAMETER TO BE VARIED"

440 INPUT Q\$

450 B $1=8$

$460 \mathrm{HI}=\mathrm{H}$

$470 \quad \mathrm{D} 1=\mathrm{D}$

$480 \quad E 1=E$

$490 \quad F 1=F$

$500 \quad A 1=A$

510 IF $E_{1}>1.0$ GO TO 1110

520 IF $A 1>45.0$ GO TO 1130

530 IF $A 1<-45.0 \mathrm{GO}$ TO 1150

540 IF $Q \$=" B^{\prime \prime}$ GO TO 640

550 IF $Q \$=1{ }^{\circ} \mathrm{H}$ " GO TO 680

560 IF $Q \$=" D "$ GO TO 720

570 IF Q\$="E" GO TO 760 


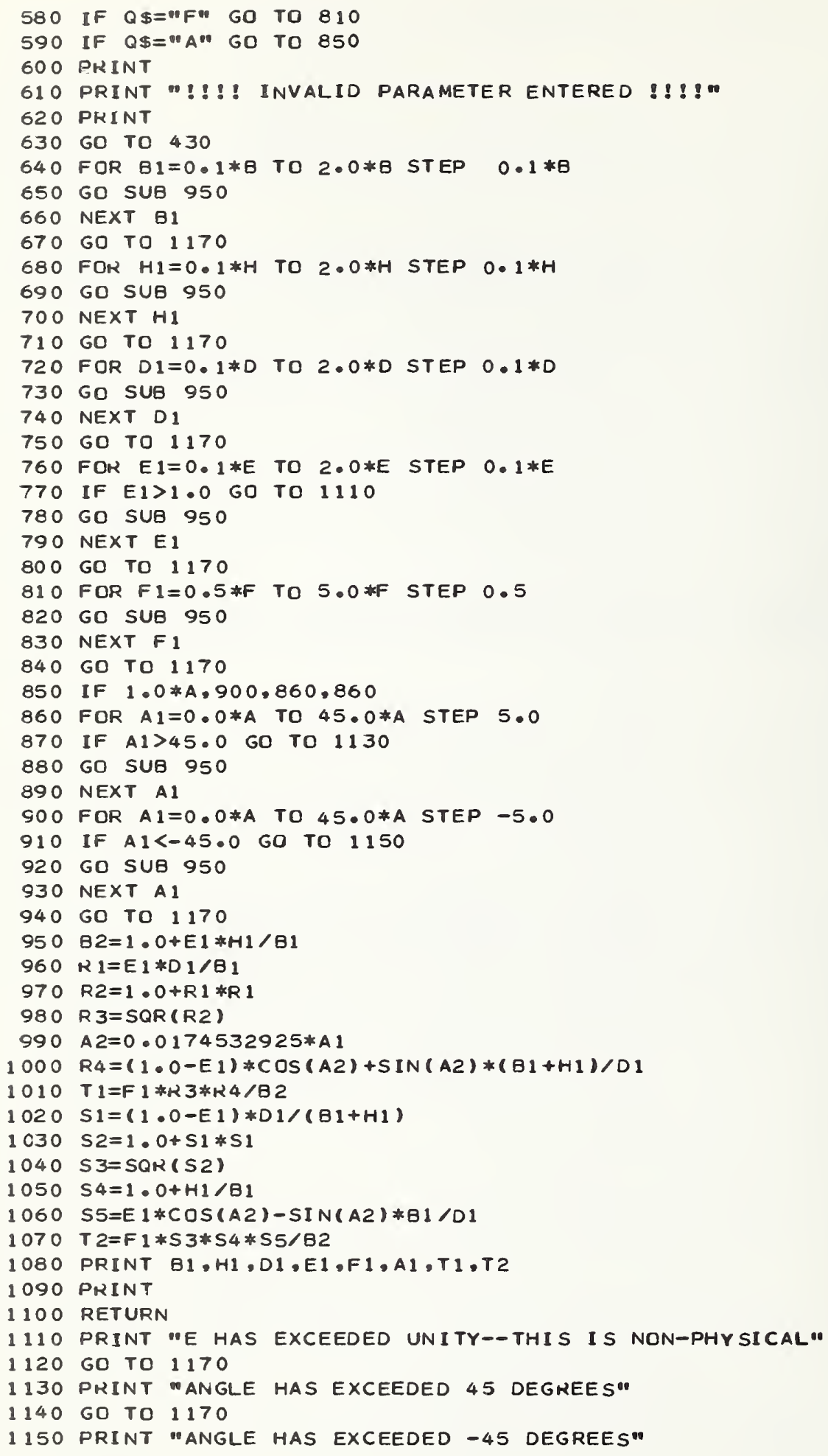




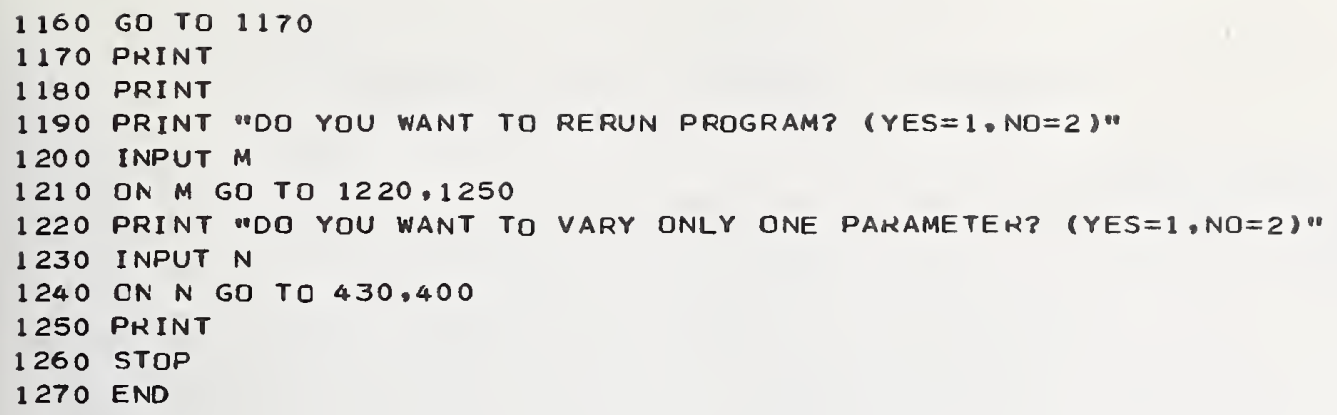


DIMENSION IN(6)

DATA (IN(I), I=1,6)/1HB, $1 \mathrm{HH}, 1 \mathrm{HD}, 1 \mathrm{HE}, 1 \mathrm{HF}, 1 \mathrm{HA} /$ WRITE $(6,10)$

FORMAT ( $1 \times, * * * * * * *$ * * *SOLUTION OF FORCES CALCULATION ** * $2 * * * * * / * * * * * * * *$ * * * DESTRUCTIVE BOND PULL TEST * * * * $3 * * * *, 1 x$ * THIS PROgRAM CALCULATES THE FORCES ON THE WIRE AT TH 4E* $1 X$, "TERMINAL AND THE DIE FROM THE BOND GEOMETRY AND THE",1X, 5 - PULL STRENGTH. / IX, B IS THE HEIGHT, at RUPTURE, OF the WIRE SPA 6N (AT THE॰, 1X, "POINT OF PULL) ABOVE THE TERMINAL",/ $1 X$,

7 'H IS THE HEIGHT OF THE TERMINAL RELATIVE TO THE DIE SURFACE*,/1X 8. -D IS THE BOND TO BOND SPACING*)

WRITE $(6,20)$

FORMAT ( $1 X$, "E IS THE DIMENSIONLESS FRACTIONAL DISTANCE ./1X,

2 BETWEEN THE TERMINAL BOND AND THE POINT OF ? WRITE $(6,30)$

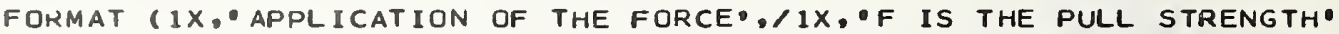
$2, / 1 X, * A$ IS THE PULL ANGLE AND IS EXPRESSED IN UNITS OF DEGREES*,

$31 X, " T I$ IS THE FORCE ON THE IRE AT THE TERMINAL, FWT: $/ 1 X$.

4 .T2 IS THE FORCE ON THE WIRE AT THE DIE, FWD, $/ 1 X$,

5 - THE VAlues OF $B, H$, AND D MAY Be EXPRESSED IN EITHER,$/ 1 x$,

6 - ENGLISH OR METRIC SO LONG aS THEY ARE CONSISTANT.*. $1 X$,

7 'THE FORCES T1 AND T2 WILl, OF COUKSE, haVE •) WRI TE $(6,40)$

2 - ANY SET OF UNITS AND NEED NOT BE CONSISTANT WITH*, $/ 1 x_{*}$

3 . THE UNITS OF B, H. AND D*)

READ (5,310) INQ

$\mathrm{E} 1=\mathrm{B}$

$H 1=H$

$D 1=D$

$E 1=E$

$F 1=F$

$A 1=A$

IF $(E 1 . G T \cdot 1.0)$ GO TO 160

IF (A 1.GT.45.) GO TO 210

IF $(A 1 \cdot L T \cdot-45$.$) GO TO 240$

DO $80 \mathrm{~J}=1.6$

IF (INQ.EQ.IN(J)) GO TO $(90,110,130,150,180,200), J$

GO TO 70

CALL PRINT (B*J*0,1,H1, D1,E1,F1,A1)

GO TO 260

DO $120 \mathrm{~J}=1,20$

CALL PRINT (B1,H*J*0,1,D1,E1,F1,A1)

GO TO 260

DO $140 \quad J=1.20$

CALL PRINT (B1,H1,D*J*0,1,E1,F1,A1)

GO TO 260

DO $170 \mathrm{~J}=1,20$

IF $(E 1 * J * 0.1 \cdot G T \cdot 1.0)$ GO TO 160

GO TO 170

WR ITE $(6,320)$

GO TO 260 
GO TO 260

DO $190 \mathrm{~J}=1,20$

190

GO TO 260

200 IF (A) 230, ,

DO $220 J=0,9$

IF $(A 1 * J * 5 . G T \cdot 45$.$) GO TO 210$

GO TO 230

210

WRITE $(6,330)$

GO TO 260

220

230

CALL PRINT $(B 1, H 1, D 1, E 1, F 1, A * J * 5)$

DO $250 \mathrm{~J}=0,9$

IF $(A 1 * J * 5 \cdot L T \cdot-45$.$) GO TO 240$

GO TO 250

240

WRITE $(6,340)$

GO TO 260

250

CALL PRINT $(B 1, H 1, D 1, L 1, F 1, A 1 * J * 5)$

GO TO 260

260 WRITE $(6,350)$

READ $(5,360) M$

GO TO $(270,280), M$

270

WRITE $(6,370)$

READ $(5,380) \mathrm{N}$

GO TO $(70,50), N$

280

290

STOP

FORMAT ()

FORMAT ( $1 X, 30 H S P E C I F Y$ PARAMETER TO $B E$ VARIED)

FORMAT ( $A_{1}$ )

FORMAT ( $1 X, 46 H$ E HAS EXCEEDED UNITY -- THIS IS NON-PHYSICAL.)

FORMAT ( $1 X, 30 \mathrm{OH}$ ANGLE HAS EXCEEDED 45 DEGREES)

FORMAT ( $1 X, 30$ HANGLE HAS EXCEEDED - 45 DEGREE $S$ )

FORMAT ( $1 X, 43 H D O$ YOU WISH TO RERUN PROGRAM? (YES=1, NO=2))

FORMAT (I 1 )

FORMAT ( $1 X, 61$ HDC YOU WISH TO VARY ONLY ONE PARAMETER? (YES = 1

2. $N O=2)$ )

380 FCRMAT (I1)

C

C

C

C

C

C

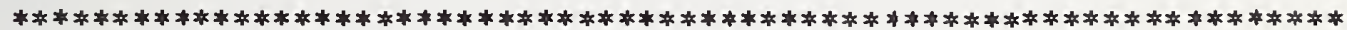

SUBRCUTINE PRINT (B1,H1,D1,E1,F1,A1)

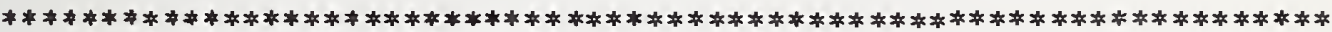

$B 2=1 \cdot 0+E 1 * H 1 / 81$

$R 1=E 1 * D 1 / B 1$

$R 2=1 \cdot 0+R 1 * R 1$

$R 3=S Q R T(R 2)$

$A 2=A 1 * 0.0174532925$

$R 4=(1 \cdot 0-E 1) * \operatorname{COS}(A 2)+\operatorname{SIN}(A 2) *(81+H 1) / 01$

$T 1=F 1 * R 3 * R 4 / B 2$

$S 1=\left(1 \cdot 0-E_{1}\right) * D_{1} /\left(B 1+H_{1}\right)$

$S 2=1 \cdot 0+S 1 * S 1$

$S 3=S Q R T(S 2)$

$S 4=1 \cdot 0+H 1 / 81$

$\mathrm{S} 5=\mathrm{E} 1 * \operatorname{COS}\left(\mathrm{A}_{2}\right)-\operatorname{SIN}\left(\mathrm{A}_{2}\right) * \mathrm{~B} 1 / \mathrm{D}_{1}$

$\mathrm{T} 2=\mathrm{F}_{1} * \mathrm{~S} 3 * \mathrm{~S} 4 * \mathrm{~S} 5 / \mathrm{B} 2$

WRITE $(6,10) \mathrm{B} 1, \mathrm{HI}_{1}, \mathrm{D}_{1}, \mathrm{E}_{1}, \mathrm{~F}_{1}, \mathrm{~A} 1, \mathrm{~T} 1, \mathrm{~T}_{2}$

RE TURN

10 FORMAT $(8(1 \times, 869 \cdot 3))$

END 


\section{Bond Pull Specifications for Large Diameter Wire}

As was indicated in the Introduction, the better understanding of the pull test has led to further developments. One of these, a bond pull specification for large diameter wire, is included in this appendix.

At the request of the Defense Electronic Supply Center a bond-pull specification for the 5- to 20-mil (0.13- to 0.51-mm) diameter aluminum wire used in JAN-TXV power transistors was developed for proposed inclusion in appropriate slash sheets to MIL-S-19500, General Specification for Semiconductor Devices. This was a difficult problem because of the many wire sizes involved (at least 10), the wide range of geometrical configurations of the transistors, and the large variety of metallurgical properties of the available wire.

In order to establish the basis for a realistic specification that offered a meaningful level of quality control and was acceptable to both users and manufacturers, five semiconductor plants were visited to obtain pull test data and other information. Two other device manufacturers contributed additional data including mean-range charts for bond pul1 tests, and acceptance criteria were supplied by several users. Three major bonding wire companies supplied information on tensile strength, elongation, and other relevant metallurgical data. Additional bond-pull data were obtained in-house on a variety of wire sizes in a limited selection of device types.

The specification developed covers bonds made of aluminum wire, with or without alloying additives, ultrasonically bonded to the die and either ultrasonically bonded or electrical-discharge welded to the post. The test, which is primarily for use on uncapped devices being assembled at the manufacturer's plant, is performed by placing a rounded metal hook under the span of wire midway between the two bonds and pulling vertically to destruction with the device clamped. In some cases soldered clips of copper or other material are permitted. These may also be tested by this procedure, but in this case the hook is placed as close as possible to the soldered joint on the die. A bond failure is designated as any bond or wire which breaks at an applied stress less than that indicated in table C1. Procedures are included in the specification for both bond failures and die fracture.

It should be noted from figure Cl that, when plotted on log-log paper, the limits for large diameter wire in table join smoothly with the limits for small diameter aluminum wire. For completeness these small wire limits are also included in the table [16].

The results of this investigation have been incorporated in MIL-STD-19500 slash sheets, for transistors. 
Table $\mathrm{Cl}$ - Bond Pull Limits

\begin{tabular}{|c|c|}
\hline Wire diameter, mils (mm) & Minimum pull 1imit, gf (N) \\
\hline $1.0 \quad(0.025)$ & $2(0.02)$ \\
\hline $1.3 \quad(0.033)$ & $3(0.03)$ \\
\hline $1.5 \quad(0.038)$ & $4 \quad(0.04)$ \\
\hline $3 \quad(0.076)$ & $12(0.12)$ \\
\hline $5 \quad(0.13)$ & $30 \quad(0.29)$ \\
\hline $8 \quad(0.20)$ & $75 \quad(0.74)$ \\
\hline $10 \quad(0.25)$ & $120(1.18)$ \\
\hline $15 \quad(0.38)$ & $220 \quad(2.16)$ \\
\hline $20 \quad(0.51)$ & $300 \quad(2.94)$ \\
\hline solder clips & $300 \quad(2.94)$ \\
\hline
\end{tabular}

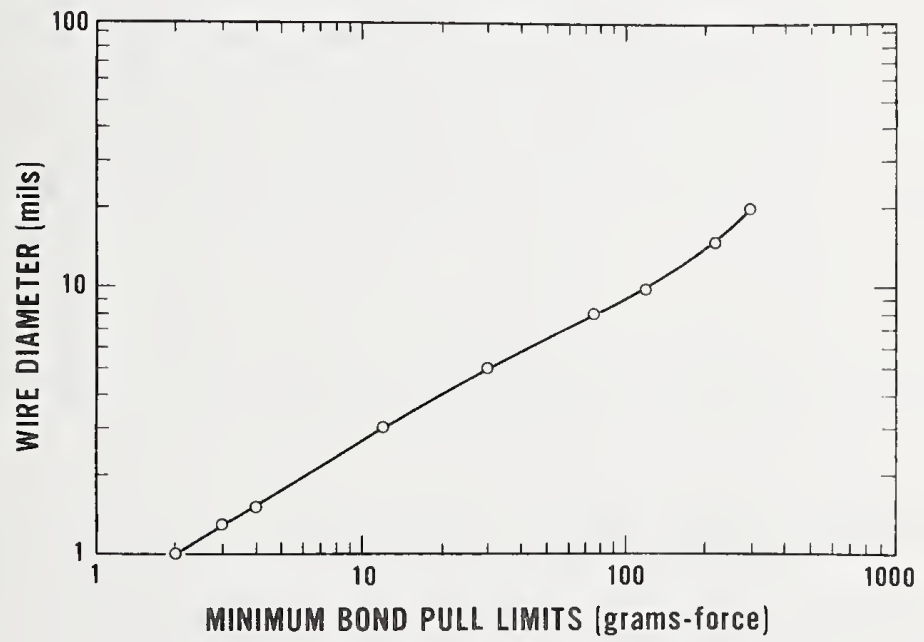

Figure $\mathrm{Cl}$. Minimum destructive bond-pull breaking-force vs wire diameter for aluminum wire bonds in semiconductor devices. 
As the bond pull test is destructive to the bond, a non-destructive bond pull test has been introduced and used by the electronics industry. However, the stress level for which the test is truly non-destructive both in the short-term and long-term sense is purely a matter of trial and error for each individual case. The work done on and the understanding resulting from the destructive bond pull test as described in this report have led to certain criteria of general applicability for the force level to be safely used in the application of the non-destructive bond pull test. The results of this investigation for aluminum and gold wire are presented in this appendix.

In view of the fact that non-destructive bond pull (NDP) tests are often used in highreliability production lines, the metallurgical and statistical rationales for the test developed, and maximum permissible NDP force limits applicable for a wide variety of wire sizes, both hard drawn and annealed were determined [17]. Previous work [18-21] on the subject has been restricted to small diameter wire having relatively low elongation under tensile stress.

The NDP test consists of pulling bonds at force levels below those necessary to cause breakage of the bond loop system. In order for the NDP test to be truly non-destructive and hence avoid the introduction of metallurgical defects in the bond loop system, no part of the bond loop system should be subjected to stresses greater than the metallurgical elastic limits.

For the NDP test to be statistically meaningful, it must be carried out in conjunction with a destructive bond pull test. The results of both the destructive bond pull test and the NDP test depend upon the same variables, including wire metallurgical properties, bonding technique, bond geometry, and bond deformation. Hence the mean and the standard deviation of the destructive bond pull test are significant factors in developing criteria for the NDP test.

In relating the results of a destructive pull test to criteria for a non-destructive pull test the stress-strain relationship of the wire is a significant factor. The effect of the state of hardness on the stress-strain relation is exemplified in figure D1. In this figure stress-strain curves are shown for the same aluminum wire in two states of hardness. The annealed wire has a large elongation typical of large diameter aluminum wire used bonding power devices. Hard-drawn or stress-relieved wire has a small elongation and is typical of that of small-diameter aluminum. wire used in bonding integrated circuits.

Bonds made with small diameter aluminum wire are typically ultrasonically welded which overworks the bond heel and causes it to be the weakest part of the bond-loop system. Hence, the strength of the heel determines the maximum safe NDP force. The heel strength depends upon the bond deformation which in turn depends upon the bonding schedule. Hence, a safe NDP force may be determined only if a destructive bond pull test is performed on bonds made under the same conditions. The results of a destructive bond pull test are assumed to follow a normal distribution for which $\bar{x}$ is the mean breaking force and $s$ is the 


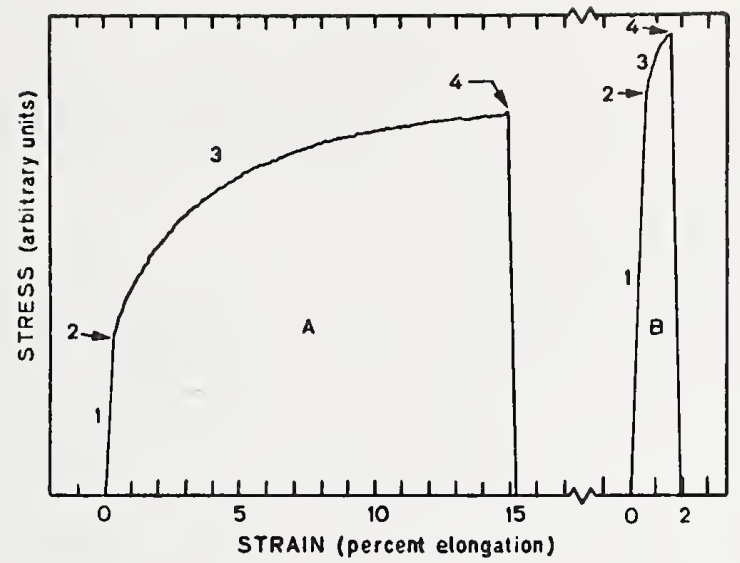

Figure D1. Stress-strain curves for annealed (A) and harddrawn or stress-relieved (B) aluminum wire. (This figure was made up from individual stress-strain charts reversed in direction for clarity of presentation. In order to display both curves on the same chart the stress axis was made relative, since the breaking load of the annealed wire was approximately one-half that of the hard-drawn wire. On both curves region 1 is the elastic region where the stress is proportional to the strain, point 2 is the proportional or elastic limit, region 3 is the region of inelastic or plastic deformation, and point 4 is the breaking load of the wire.)

Table DI - Summary of NDP Force Recommendations

Type of Production Line Composition Elongation
Relation Between $\bar{x}$ and $s$ Recommended on the Bond Pull Test Maximum Safe NDP Force

\begin{tabular}{ccccc}
\hline Normal & Aluminum & $<3 \%$ & $0.15 \bar{x}<s \leqslant 0.25 \bar{x}$ & $0.9(\bar{x}-3 s)$ \\
High Rel & Aluminum & $<3 \%$ & $s \leqslant 0.15 \bar{x}$ & $0.9(\bar{x}-4 s)$ \\
A11 & Aluminum & $\sim 5$ to $20 \%$ & $s \leqslant 0.25 \bar{x}$ & $(\bar{x}-3 s) / 2$ \\
& Aluminum & $>20 \%$ & $s \leqslant 0.25 \bar{x}$ & $(\bar{x}-3 s) / 3$ \\
A11 & Gold & Any & $0.15 \bar{x}<s \leqslant 0.25 \bar{x}$ & $0.7(\bar{x}-3 s)$ \\
& Gold & Any & $s \leqslant 0.15 \bar{x}$ & $0.7(\bar{x}-4 s)$ \\
\hline
\end{tabular}


sample standard deviation of the distribution. For normal assembly lines, where $\mathrm{s}$ can be expected to lie in the range $0.15 \overline{\mathrm{x}}$ to $0.25 \overline{\mathrm{x}}$ the recommended maximum safe NDP force is $0.9(\bar{x}-3 s)$. For high-reliability lines, s may be equal to or less than $0.15 \bar{x}$. For this case, the recommended maximum safe NDP force is $0.9(\bar{x}-4 s)$. No NDP testing is recommended for cases where $\mathrm{s}$ is greater than $0.25 \overline{\mathrm{x}}$ since this indicates that some aspect of the bonding procedure is out of control and either a low, meaningless NDP force would be used or too many bonds would be stressed beyond their elastic limits.

The large diameter aluminum wire used in power devices typically has an elongation up to 20 percent before breaking. Also, this wire is usually ultrasonically bonded with a grooved capillary-type tool which limits the maximum bond deformation and hence does not produce a weak bond heel. In this case, the stress-strain relation for the wire span determines the maximum safe NDP force. Due to the differences in the stress-strain relation from that of small diameter wire, a different NDP force is necessary. For a wire elongation up to 20 percent and an $s$ of $0.25 \bar{x}$ or less the recommended maximum safe NDP force is $(\bar{x}-3 s) / 2$. For an elongation greater than 20 percent, the maximum NDP force must be reduced to $(\bar{x}-3 s) / 3$ in order to avoid significant inelastic wire elongation during the test.

Gold wire bonds formed by thermocompression or ultrasonic techniques do not have weak, overworked bond heels. Hence, the stress-strain relation for wire span determines the NDP force. These relations for small diameter grain-stabilized gold wire used in both ultrasonic and thermocompression bonding show that this type of gold wire typically experiences most of its elongation above 85 to 90 percent of its breaking load. However, some other gold wires may begin to elongate as low as 70 percent of their breaking load. Considering this and the high pull strength, even with large bond deformation, the recommended maximum safe NDP force control limit to include all small diameter gold wire is $0.7(\bar{x}-3 \mathrm{~s})$ or $0.7(\bar{x}-4 s)$ for $0.15 \bar{x} \leq s \leq 0.25 \bar{x}$ or $s \leq 0.15 \bar{x}$, respectively.

Table D1 sumarizes these recommendations. It must be noted that the NDP test ensures the reliability of a bond at the time of the test but does not prevent the later failure of the bond from intermetallic compound formation or post-production stresses [22]. 


\section{Announcement of New Publications on Semiconductor Measurement Technology}

Superintendent of Documents, Government Printing Office, Washington, D.C. 20402

Dear Sir:

Please add my name to the announcement list of new publications to be issued in the series: National Bureau of Standards Special Publication $400-$.

Name

Company

Address

City State Zip Code

(Notification Key N-413) 


\section{PERIODICALS}

JOURNAL OF RESEARCH reports National Bureau of Standards research and development in physics, mathematics, and chemistry. It is published in two sections, available separately:

\section{- Physics and Chemistry (Section A)}

Papers of interest primarily to scientists working in these fields. This section covers a broad range of physical and chemical research, with major emphasis on standards of physical measurement, fundamental constants, and properties of matter. Issued six times a year. Annual subscription: Domestic, $\$ 17.00$; Foreign, $\$ 21.25$.

\section{- Mathematical Sciences (Section B)}

Studies and compilations designed mainly for the mathematician and theoretical physicist. Topics in mathematical statistics, theory of experiment design, numerical analysis, theoretical physics and chemistry, logical design and programming of computers and computer systems. Short numerical tables. Issued quarterly. Annual subscription: Domestic, \$9.00; Foreign, \$11.25.

DIMENSIONS/NBS (formerly Technical News Bulletin)-This monthly magazine is published to inform scientists, engineers, businessmen, industry, teachers, students, and consumers of the latest advances in science and technology, with primary emphasis on the work at NBS. The magazine highlights and reviews such issues as energy research, fire protection, building technology, metric conversion, pollution abatement, health and safety, and consumer product performance. In addition, it reports the results of Bureau programs in measurement standards and techniques, properties of matter and materials, engineering standards and services, instrumentation, and automatic data processing.

Annual subscription: Domestic, $\$ 9.45$; Foreign, $\$ 11.85$.

\section{MONPERIODICALS}

Monographs-Major contributions to the technical literature on various subjects related to the Bureau's scientific and technical activities.

Handbooks-Recommended codes of engineering and industrial practice (including safety codes) developed in cooperation with interested industries, professional organizations, and regulatory bodies.

Special Publications-Include proceedings of conferences sponsored by NBS, NBS annual reports, and other special publications appropriate to this grouping such as wall charts, pocket cards, and bibliographies.

Applied Mathematics Series-Mathematical tables, manuals, and studies of special interest to physicists, engineers, chemists, biologists, mathematicians, computer programmers, and other engaged in scientific and technical work.

National Standard Reference Data Series-Provides quantitative data on the physical and chemical properties of materials, compiled from the world's literature and critically evaluated. Developed under a world-wide program coordinated by NBS. Program under authority of National Standard Data Act (Public Law 90-396).

NOTE: At present the principal publication outlet for these data is the Journal of Physical and Chemical Reference Data (JPCRD) published quarterly for NBS by the American Chemical Society (ACS) and the American Institute of Physics (AIP). Subscriptions, reprints, and supplements available from ACS, 1155 Sixteenth St. N. W., Wash. D. C. 20056.

Building Science Series-Disseminates technical information developed at the Bureau on building materials, components, systems, and whole structures. The series presents research results, test methods, and performance criteria related to the structural and environmental functions and the durability and safety characteristics of building elements and systems.

Technical Notes-Studies or reports which are complete in themselves but restrictive in their treatment of a subject. Analogous to monographs but not so comprehensive in scope or definitive in treatment of the subject area. Often serve as a vehicle for final reports of work performed at NBS under the sponsorship of other government agencies.

Voluntary Product Standards-Developed under procedures published by the Department of Commerce in Part 10, Title 15, of the Code of Federal Regulations. The purpose of the standards is to establish nationally recognized requirements for products, and to provide all concerned interests with a basis for common understanding of the characteristics of the products. NBS administers this program as a supplement to the activities of the private sector standardizing organizations.

Federal Information Processing Standards Publications (FIPS PUBS)-Publications in this series collectively constitute the Federal Information Processing Standards Register. Register serves as the official source of information in the Federal Government regarding standards issued by NBS pursuant to the Federal Property and Administrative Services Act of 1949 as amended, Public Law 89-306 (79 Stat. 1127), and as implemented by Executive Order 11717 (38 FR 12315, dated May 11, 1973) and Part 6 of Title $15 \mathrm{CFR}$ (Code of Federal Regulations).

Consumer Information Series-Practical information, based on NBS research and experience, covering areas of interest to the consumer. Easily understandable language and illustrations provide useful background knowledge for shopping in today's technological marketplace.

NBS Interagency Reports (NBSIR)-A special series of interim or final reports on work performed by NBS for outside sponsors (both government and non-government). In general, initial distribution is handled by the sponsor; public distribution is by the National Technical Information Service (Springfield, Va. 22161) in paper copy or microfiche form.

Order NBS publications (except NBSIR's and Bibliographic Subscription Services) from: Superintendent of Documents, Government Printing Office, Washington, D.C. 20402 .

\section{BIBLIOGRAPHIC SUBSCRIPTION SERVICES}

The following current-awareness and literature-survey bibliographies are issued periodically by the Bureau: Cryogenic Data Center Current Awarenew Service

A literature survey issued biweekly. Annual subscription: Domestic, $\$ 20.00$; foreign, $\$ 25.00$.

Liquefied Natural Gas. A literature, survey issued quarterly. Annual subscription: $\$ 20.00$. survey issued quarterly. Annual subscription: $\$ 20.00$. Send subscription orders and remittances for the preceding bibliographic services to National $\mathrm{Bu}-$ reau of Standards, Cryogenic Data Center (275.02) Boulder, Colorado 80302.

Electromagnetic Metrology Current Awareness Service Issued monthly. Annual subscription: \$24.00. Send subscription order and remittance to Electromagnetics Division, National Bureau of Standards, Boulder, Colo. 80302 . 
